Linköping Studies in Science and Technology.

Dissertation No. 1907

\title{
Organs-on-chips for the pharmaceutical development process: \\ design perspectives and implementations
}

Jonas Christoffersson

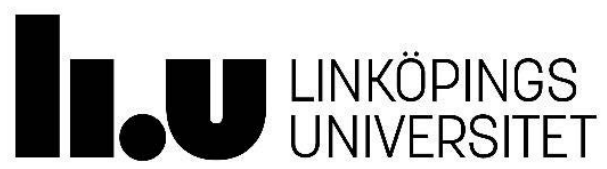

Division of Biotechnology

Department of Physics, Chemistry and Biology

Linköpings universitet, SE-581 83 Linköping, Sweden

Linköping 2018 
Cover: Illustration of a perfused microbioreactor inhabited by primary endothelial cells stained to visualize living cells (green), dead cells (red), and cell nuclei (blue).

During the course of the research underlying this thesis, Jonas Christoffersson was enrolled in Forum Scientium, a multidisciplinary doctoral program at Linköping University, Sweden

(C) Jonas Christoffersson, 2018

Printed in Sweden by LiU-Tryck, Linköping, Sweden

ISSN 0345-7524

ISBN 978-91-7685-359-7 


\section{Abstract}

Organs-on-chips are dynamic cell culture devices created with the intention to mimic organ function in vitro. Their purpose is to assess the toxicity and efficacy of drugs and, as early as possible in the pharmaceutical development process, predict the outcome of clinical trials. The aim of this thesis is to explain and discuss these cell culture devices from a design perspective and to experimentally exemplify some of the specific functions that characterize organs-on-chips.

The cells in our body reside in complex environments with chemical and mechanical cues that affect their function and purpose. Such a complex environment is difficult to recreate in the laboratory and has therefore been overlooked in favor of more simple models, i.e. static twodimensional (2D) cell cultures. Numerous recent reports have shown cell culture systems that can resemble the cell's natural habitat and enhance cell functionality and thereby potentially provide results that better reflects animal and human trials. The way these organs-on-chips improve in vitro cell culture assays is to include e.g. a three-dimensional cell architecture (3D), mechanical stimuli, gradients of oxygen or nutrients, or by combining several relevant cell types that affect each other in close proximity.

The research conducted for this thesis shows how cells in 3D spheroids or in 3D hydrogels can be cultured in perfused microbioreactors. Furthermore, a pump based on electroosmosis, and a method for an objective conceptual design process, is introduced to the field of organs-on-chips.

Keywords: Organs-on-chips, cell culture models, pharmaceutical development, microfluidics 


\section{Populärvetenskaplig sammanfattning}

Organs-on-chips är modellsystem med avsikt att återskapa ett organs funktion in vitro genom att odla celler från djur eller människor i en omgivning som efterliknar kroppen. Syftet med dessa modeller är att utvärdera ett potentiellt läkemedels toxicitet och effektivitet så tidigt som möjligt i läkemedelsutvecklingen för att kunna förutsäga hur det påverkar människor. Målet med denna avhandling är att förklara och diskutera denna typ av cellmodeller utifrån ett designperspektiv och experimentellt visa några av de specifika funktioner som är en del av konceptet organs-on-chips.

Cellerna i våra kroppar befinner sig komplexa miljöer med kemiska och mekaniska signaler som påverkar deras funktion och syfte. Sådana miljöer är svåra att återskapa på laboratoriet och har därför till stor del förbisetts till fördel för enklare modellsystem som ofta består av celler som odlas på plast- eller glasytor under statiska förhållanden. På senare tid har en betydande mängd publikationer visat på att cellmodeller som bättre kan efterlikna cellens naturliga miljö kan förbättra dess olika funktioner och därmed ge resultat som eventuellt kan matcha försöken som görs på djur och människor. Det finns flera olika funktioner, hämtade från vår kunskap om människans biologi, som organs-on-chips kan implementera för att skapa dessa förbättrade cellmiljöer och inkluderar en tre-dimensionell omgivning, skjuvkrafter från flöden av vätskor, gradienter av syre och näringsämnen, eller en kombination av flera olika relevanta celltyper som påverkar varandra i samma modell.

Forskningen som utförts inför den här avhandlingen visar hur sfäroider och hydrogeler kan användas för att skapa tredimensionella cellmiljöer i dynamiska mikrobioreaktorer. Dessutom demonstreras hur en pump som drivs med elektroosmos kan skapa tillräckligt höga flödeshastigheter för att påverka cellers morfologi i ett mikrosystem. Slutligen implementeras en konceptuell designmetodologi på organson-chips i ett försök att visa en objektiv designprocess för att ta fram nya prototyper. 


\section{List of Publications}

This thesis is based on the following publications:

\section{Paper I}

Gunnar Bergström*, Jonas Christoffersson*, Kristin Schwanke, Robert Zweigerdt, and Carl-Fredrik Mandenius

Stem cell derived in vivo-like human cardiac bodies in a microfluidic device for toxicity testing by beating frequency imaging

Lab on a Chip, 2015, 15, 3242

Contribution: Planned, performed microfluidic device experiments, and produced and analyzed the data together with GB. Wrote the manuscript together with the co-authors.

\section{Paper II}

Jonas Christoffersson, Florian Meier, Henning Kempf, Kristin Schwanke, Michelle Coffee, Mario Beilmann, Robert Zweigerdt, and Carl-Fredrik Mandenius

A cardiac cell outgrowth assay for evaluating drug compounds using a cardiac spheroid-on-a-chip device

Manuscript

Contribution: Planned and performed microfluidic device experiments. Analyzed the data together with FM. Wrote the manuscript together with the co-authors.

\section{Paper III}

Katarina Bengtsson*, Jonas Christoffersson*, Carl-Fredrik Mandenius, and Nathaniel D. Robinson

A clip-on electroosmotic pump for oscillating flow in microfluidic cell culture devices

Microfluidics and Nanofluidics, Accepted Manuscript, 2018

Contribution: Planned, modified the pump for microfluidic device integration, performed cell experiments, and obtained and analyzed the cell-based data together with KB. Wrote the manuscript together with the co-authors. 
Paper IV

Jonas Christoffersson*, Christopher Aronsson*, Michael Jury, Robert Selegård, Daniel Aili, and Carl-Fredrik Mandenius

Bioorthogonally crosslinked hyaluronan-poly(ethylene glycol)-RGD hydrogels for supporting hepatic cells in a perfused liver-on-a-chip Submitted

Contribution: Planned, performed microfluidic device experiments, and obtained cell-based data. Planned and analyzed the data together with CA. Wrote the manuscript together with the co-authors.

\section{Paper V}

Jonas Christoffersson, Danny van Noort, and Carl-Fredrik Mandenius Developing organ-on-a-chip concepts using bio-mechatronic design Methodology

Biofabrication, 2017, 9, 025023

Contribution: Planned and performed research behind the paper. Discussed the content and wrote the manuscript together with the coauthors.

* These authors contributed equally to the paper 


\section{Publications not included in this thesis}

Jonas Christoffersson, Gunnar Bergström, Kristin Schwanke, Henning Kempf, Robert Zweigerdt, and Carl-Fredrik Mandenius

A microfluidic bioreactor for toxicity testing of stem cell derived 3D cardiac bodies

Bioreactors in Stem Cell Biology: Methods and Protocols, Turksen, K., Ed. Springer New York: New York, NY, 2016; pp 159-168

Erica Zeglio, Sara I. Liin, Fredrik Elinder, Jonas Christoffersson, Jens Eriksson, Deyu Tu, Martina M. Schmidt, Mukundan Thelakkat, Roger Gabrielsson, Niclas Solin, and Olle Inganäs

Electronic membranes for bioelectrochemical transistor devices Manuscript

Christopher Aronsson, Robert Selegård, Jonas Christoffersson, CarlFredrik Mandenius, and Daniel Aili

Supramolecular functionalization and tuning of peptide modified bio-orthogonally crosslinked hyaluronan-poly(ethylene glycol) hydrogels

Manuscript 


\section{Table of Contents}

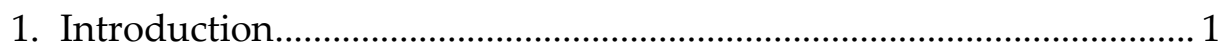

1.1. The pharmaceutical development process ....................................... 3

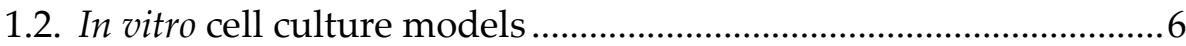

1.3. The concept of organs-on-chips ................................................... 8

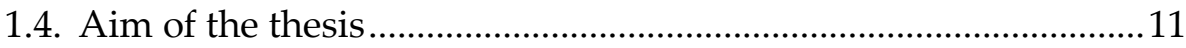

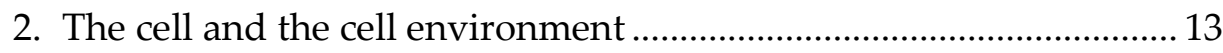

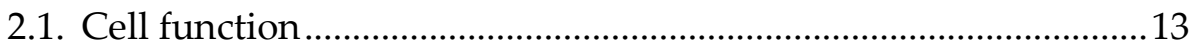

2.1.1 Contraction and relaxation of cardiomyocytes........................ 13

2.1.2 Protein synthesis.............................................................. 15

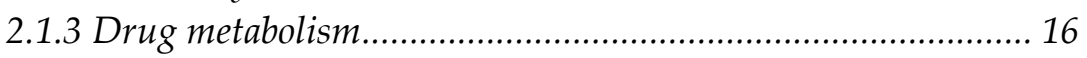

2.2. Cell-cell communication and co-cultures.......................................16

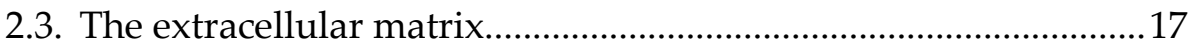

2.4. The role of shear stress and the dynamic in vivo environment....18

2.5. The difference between cells in 2D and cells in 3D ......................20

2.6. Cell types and cell lines for in vitro models ....................................20

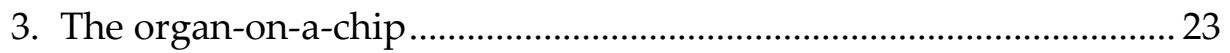

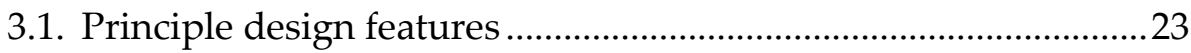

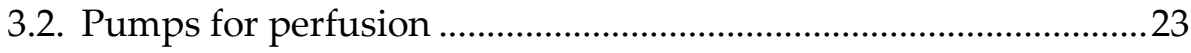

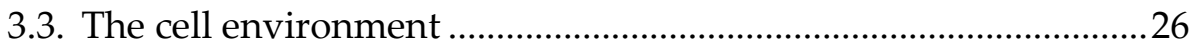

3.3.1 Mechanical stimuli of cells................................................... 26

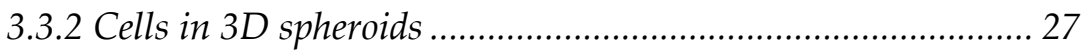

3.3.3 Hydrogels to mimic the ECM for cell support ....................... 27

3.3.4 Spatial localization and microstructures ............................... 29

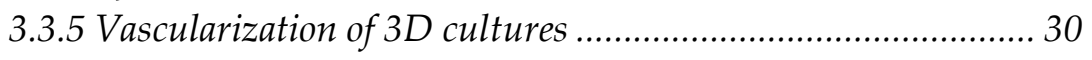

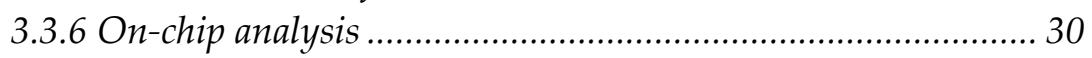

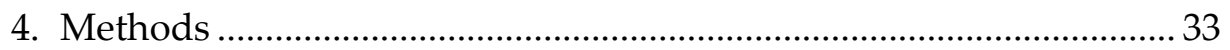

4.1. Photolithography for master fabrication.........................................33

4.2. Soft lithography for replica molding in PDMS ............................... 35

4.3. Microfluidics to provide organs-on-chips with physiological

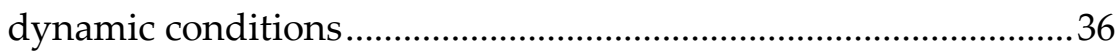

4.4. Electroosmotic flow as an alternative to mechanically generated

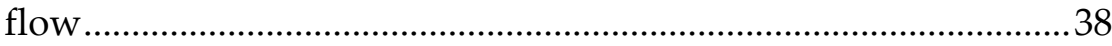

4.5. Hydrogels to mimic the support function of ECM in vitro............40

4.6. Microbioreactors as generic organs-on-chips.................................. 41 


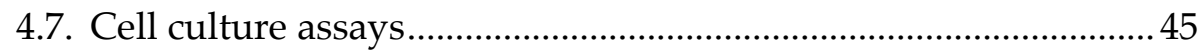

4.7.1 Live/Dead assay ................................................................. 45

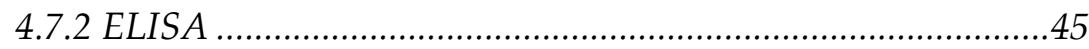

4.7.3 Image processing and image analysis of cell cultures...............46

4.8. Conceptual design methodology for product development........ 49

5. Conclusion and further perspectives................................................... 53

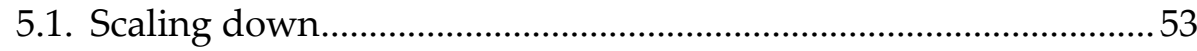

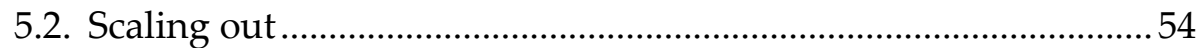

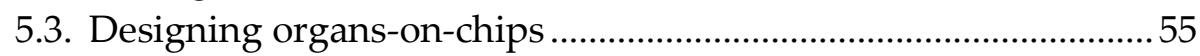

5.4. Further perspectives ....................................................................... 55

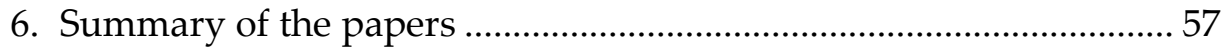

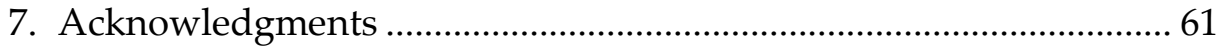

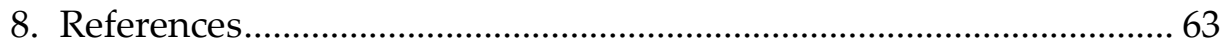




\section{Introduction}

This thesis is based on the idea of using organs-on-chips as cell culture models to better understand the effects of drugs during the pre-clinical phase of the pharmaceutical development process. The conducted research takes a step away from traditional static two-dimensional (2D) cell culture models in favor of perfused and three-dimensional (3D) models to advance towards organs-on-chips. In this first chapter, today's principles of drug discovery and development are briefly presented and related to how organs-on-chips can support a faster process for more reliable and better suited pharmaceuticals. The second chapter of the thesis describes the cell in general, some of the cells functions, and the cell environment as an overview of what a cell culture model should aim to recreate. In the third chapter, the organ-on-a-chip is divided into specific functions with technological features regarding perfusion, cell culture environment, and analysis. The fourth chapter contains the main methods used during this thesis. Concluding remarks based on the thesis and the included papers are given in chapter five.

Most pharmaceutical candidates fail because of one of two reasons; 1) it does not work, or 2) it is not safe [1]. A pharmaceutical substance is therefore extensively tested and must show significant positive effects and limited side effects, before being launched as a safe and potent drug product for administration to patients. The potential effects of drug candidates are investigated using a range of methods; from computer models and in vitro cell cultures, to animal testing and finally clinical trials in humans. In vitro methods are experiments that can be conducted outside a living organism with cells from animals or humans grown in the laboratory and analyzed using a range of different assays to investigate how a certain chemical or stimuli affects their survival and function. This thesis focuses on the part of the pharmaceutical development process in vitro models are used to evaluate a drug compound. The definition of a cell culture model is here defined as an $e x$ vivo representation of the cell and the cell's in vivo environment, performed in vitro. In recent years, a high number of publications show that these cell culture models could benefit from incorporating a more 
physiologically relevant environment, a concept that has become known as organ-on-a-chip devices [2].

The general term for the study of how chemicals affect living organisms is known as toxicology and has its backgrounds in the work performed by Mathieu Orfilia in the beginning of the $19^{\text {th }}$ century [3]. However, the study on how plants, animals, and everything else in our surroundings affect us has, of course, been around much longer, probably, to some extent, through the whole human history. During the development of pharmaceuticals, the toxicology of a drug is one of three major consideration that must be included in the process. The drug administered to a patient must not cause any adverse effects which means that the side effects of a drug should be non-existing or minimal (depending on the disease). Several cases where pharmaceuticals have caused unintended, unforeseen, and unacceptable effects have been reported during the last century. One of the most referred events is probably the catastrophic effect of recommending thalidomide (known as Neurosedyn in Sweden) as a sleeping aid for pregnant women during the late 1950s and early 1960s which resulted in death or severe injuries in more than 10000 children [4]. The second consideration concerns the ethics of the experiments. Before conducting research involving animals and humans it must first be presented and pass the board of an ethical committee that values the benefits against the potential harm. A concrete incentive to replace animal experiments with alternative testing methods can be found in the European Union's complete ban, from 2013, on sale and marketing of cosmetics that have been tested on animals [5]. From a diverse collection of private and public organizations, strategies and guidelines for the reduction of animal experiments have been suggested and implemented, for example by the American National Academy of Science, the International Council for Harmonisation of Technical Requirements for Pharmaceuticals for Human Use (ICH), the European Commission directive 3R, and in Sweden by the academic research center Swetox [6-9]. The third essential consideration is the economics of the product. The new drug must be possible to manufacture and market at a reasonable price and still carry the economic burden of all the basic research, the development process, as 
well as the substances that do not end up as commercial products. Governing these parameters and a major part of the development process are national and international regulatory agencies who give approval for commercial use on specific markets to pharmaceuticals that comply with safety and efficacy regulations.

With these three considerations in mind (toxicology, ethics, and economics), the potential of using in vitro based methods for drug discovery is very appealing. It also includes cell culture-based methods, which are within the frame of this thesis, where the cells from animals or humans are grown in the laboratory and analyzed using a range of different assays to investigate how a certain chemical or stimuli affects their survival and function.

\subsection{The pharmaceutical development process}

The work carried out to bring a new potential pharmaceutical substance from its discovery to the commercial market is called the pharmaceutical development process (Figure 1.1). The process begins with the basic research conducted at both industrial and academic sites where new knowledge and insights about a certain disease might lead to the identification of a target. The target can for example be a receptor on the cell surface that tells the cell to start producing a specific protein or change its intracellular activity (Figure 1.2). The researchers then need to characterize the target to learn about its composition and structure. This is important because the pharmaceutical that is being developed should have both a high affinity and a high specificity for the target. Ideally, the drug compound binds and interacts perfectly with the target but not to any other similar targets in the body. Large compound libraries containing information about chemicals and molecules in combination with bioinformatics are used to find the molecules and proteins that interact with the target. Thousands of interesting chemical substances can be discovered this way, however, many of them are rejected early based on previous knowledge about efficacy, toxicity, or difficulties in manufacturing. The rest of the substances, known as drug leads, are screened using high-throughput methods for analysis of binding mechanisms, kinetics, selectivity etc., resulting in a few hundred 
- Basic research

- Disease knowledge

- Target identification

- Target characterization
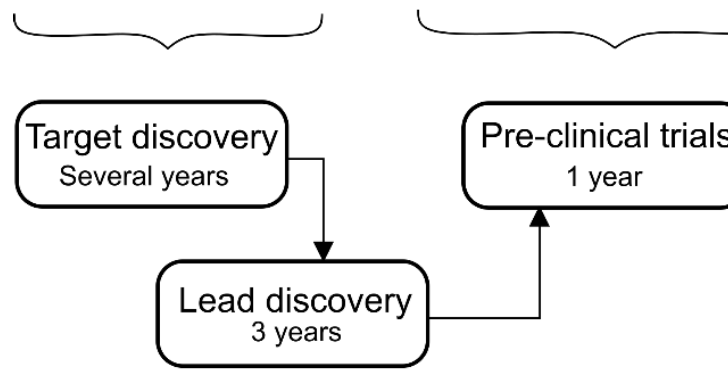

- Cell cultures in vitro

- Animal experiments in vivo

- Toxicity and safety screening

- ADME

- Drug candidates identification

- Clinical trial application
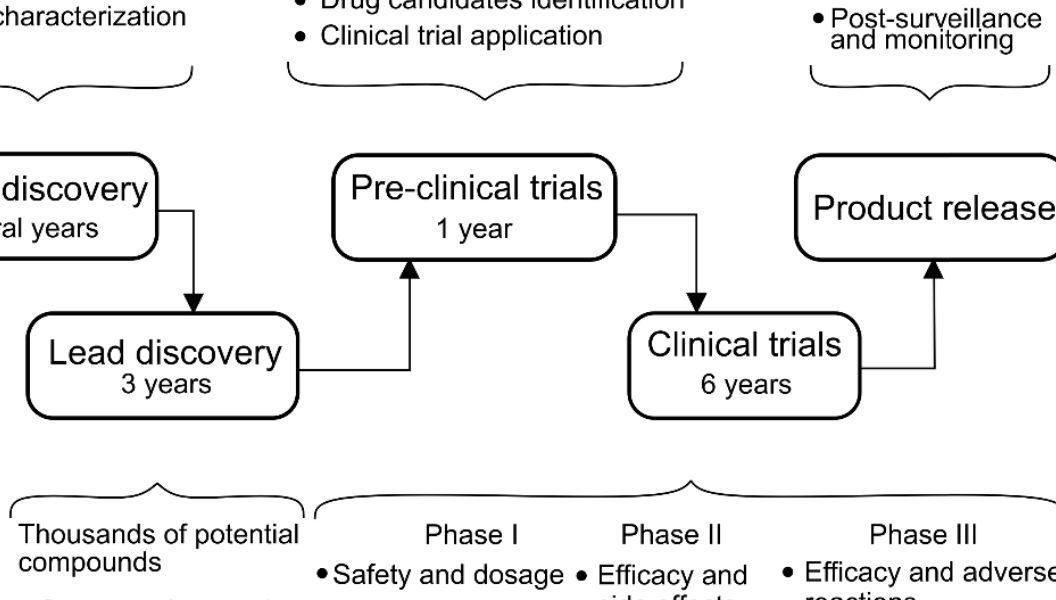

- Compound screening

-

20-100 healthy volunteers

5 potential compounds

\section{Phase I}

Safety and dosage

age

Several hundred volunteers with the disease

\section{3-4 potential} compounds

\section{Phase II}

Efficacy and side effects

\section{- Efficacy and adverse} reactions

- Review by authorities 300 - 3000 volunteers with the disease

1-2 potential compounds

\section{Cost}

Figure 1.1 An overview of the pharmaceutical development process and an approximate timeline. A target is identified and characterized during basic research. Compounds are screened to find drug leads that bind with high affinity and specificity towards the target. The drug leads enter the pre-clinical trials where the research is focused on the drug's absorption, distribution, metabolism, and excretion (ADME) and its toxicity. The best drug leads can become drug candidates if the clinical trial application is approved by the regulatory agency. The drug candidates enter the clinical trials where the drug is tested on humans in three phases (Phase I-III). If a candidate meets the requirements on efficacy and safety, it can be released as a commercial product. However, effects of the drug will be observed throughout the product's life cycle.

contenders. These drug leads are further screened in more advanced biological contexts by testing how a substance affects cells and tissues in 


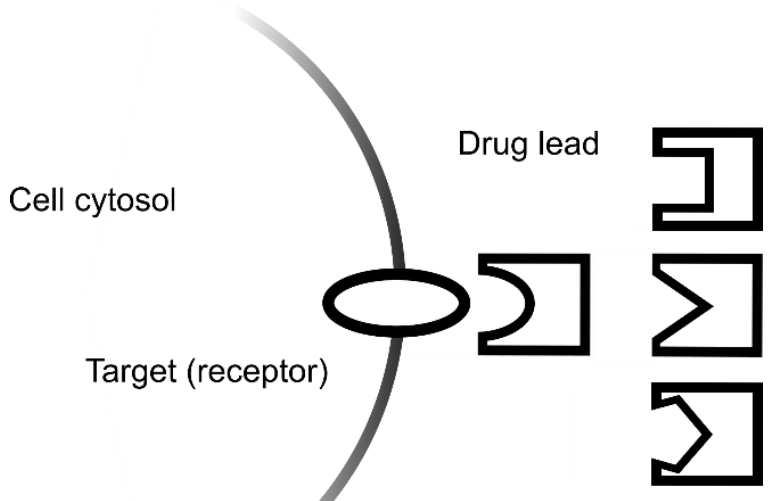

Figure 1.2 Drug candidates are chemical substances that can interact with a target, for example the receptor on the surface of a cell. The optimal drug candidate has high affinity and high specificity to the target.

vitro as well as animals in vivo. The questions to be answered during this part of the process concerns the toxicity and safety of the candidates and include information about the pathways of absorption, distribution, metabolism and excretion (ADME) in a living organism [10]. The preclinical phase should result in a few appropriate drug candidates with documented affinity and specificity towards a well described target and proved to be safe for use in animals. After approval from national regulatory agencies, the candidates that best fulfill these criteria can enter the clinical trials where the they are tested in humans. The clinical trials are divided into three phases (I-III) with the purpose to validate the toxicity and ADME pathways from the pre-clinical trials, as well as to define the efficacy towards the specific disease in humans [11]. The first phase (Phase I) is conducted on healthy volunteers to show the safety in humans and define the appropriate dosages, or drug concentrations, that can be used without severe side effects. In the next steps, volunteers affected by the disease or condition intended to treat, are recruited for studies on efficacy and to monitor the side effects, first in a small scale involving 20-100 persons (Phase II) and subsequently at large scale with 300-3000 individuals (Phase III) [12]. A successful candidate can be approved for release as a commercial product after careful and objective review by national and international regulatory agencies of all data generated throughout the development process. 
However, post-surveillance and monitoring of the product by collection of information about effects and side effects are continuously reported from the medical communities. If a pharmaceutical is reported to have unacceptable adverse effects, it can be withdrawn from the market [13].

The entire pharmaceutical development process can take around 12-15 years to accomplish with total costs exceeding $\$ 1$ billion $[1,11]$. The price of a pharmaceutical must cover both the basic research and all the preclinical and clinical trials as well as the manufacturing expenses. Furthermore, it must cover the cost of the substances that failed and were rejected somewhere along the development process. It would be desirable to find methods and procedures to shorten the development process for a pharmaceutical to reach the customers faster and thereby at a lower price. However, the rigorous testing of drug candidates on humans in clinical trials before product release are not likely to disappear in the near future. Hence, as the clinical trials impose the major cost of the pharmaceutical development process, finding the "bad" candidates as early as possible could save both money and possibly also minimize the number of ethically conflicted animal experiments. By establishing methods using in vitro models of certain tissues or organs with cells of human or animal origin, researchers have been able to create platforms for determining the toxicity and efficacy of drug candidates. The challenge is to know how well these results translate to the clinical trials, i.e. if the cells response in the laboratory is similar to the cell's response in the patient.

\subsection{In vitro cell culture models}

Cell culture models are used during the pre-clinical phase before and in parallel with animal experiments [1]. Such a model can, for example, consist of liver cells grown on a transparent plastic surface. When these cells are exposed to a chemical substance, e.g. acetaminophen (also known as paracetamol), different methods to determine the cells viability and the cells functions are used to evaluate the chemical's effects at certain concentrations. The simplicity of these models makes them suitable for high-throughput screenings and a massive market has evolved to support the investigations by offering everything from 


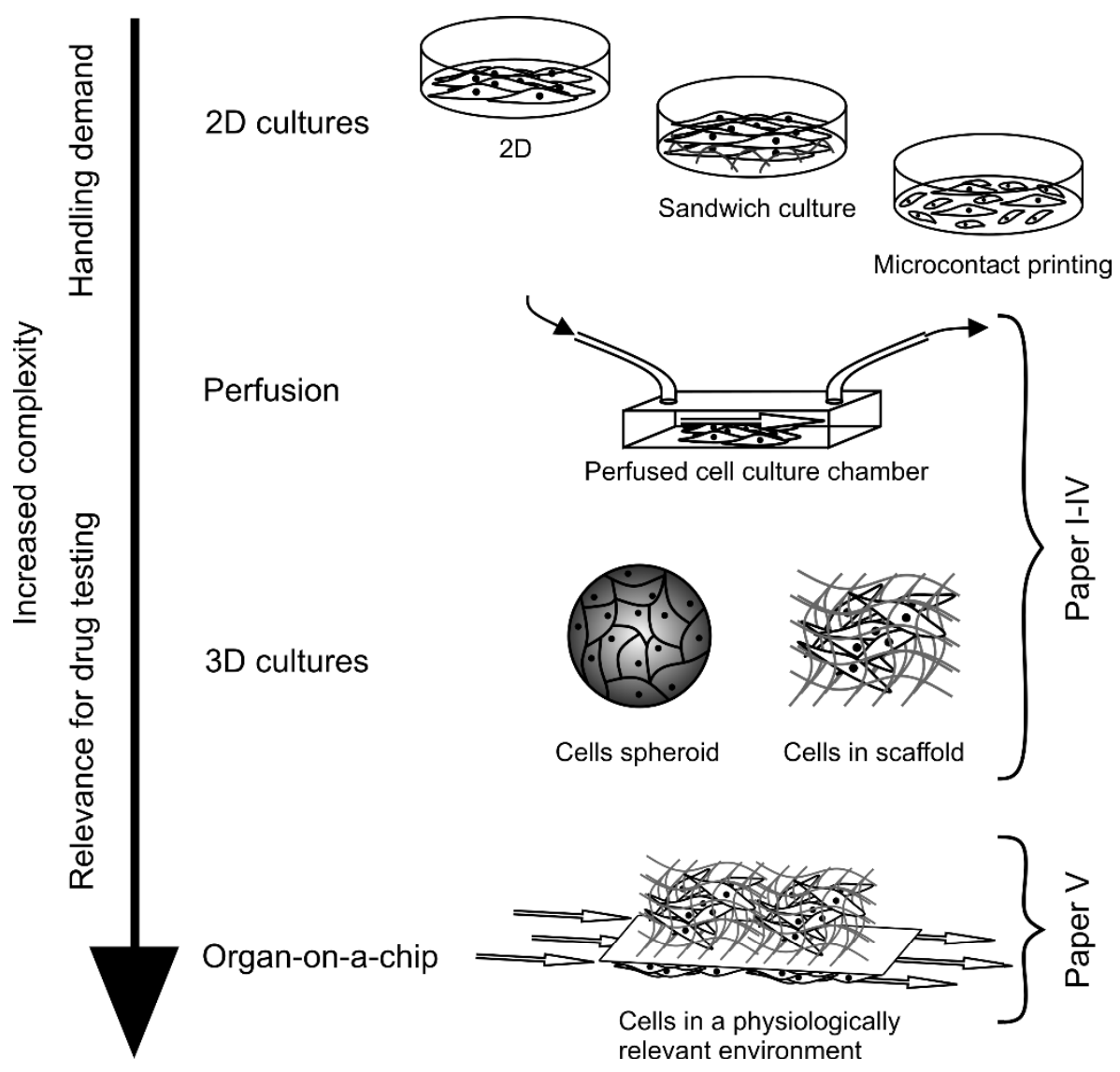

Figure 1.3. Different types of cell culture models for pharmaceutical testing in vitro arranged based on their handling demand (ease of use) and their potential relevance for drug testing.

consumables and specially designed kits of chemicals, to advanced instruments for analysis such as a range of different microscopes and spectrophotometers, often in standardized formats for compatibility. However, most cell culture models are relatively simple and can only give limited information about the mechanisms of a drug candidate (Figure 1.3). That is, the tests conducted on these cell cultures does not give the complete picture about the ADME pathways that can be extracted from animal and human experiments. The reason is that cells cultured on a glass or plastic substrates in the laboratory differ significantly from cells growing and living inside our bodies. It could therefore be of advantage to create more complex cell culture models 
where the cells can reside in a setting with chemical and physical cues to enhance their functionality. Over the last decade, platforms for such technologies have become known as organ-on-a-chip devices.

\subsection{The concept of organs-on-chips}

Organs-on-chips are perfused microdevices inhabited by cells in cultures that mimic the cell's physiological environment [2,14-17]. The intention of an organ-on-a-chip is to create a bioanalytical platform where it is possible to study how a cell population reacts to certain chemicals or stimuli in a situation that closely resembles the environment of a certain tissue or organ. The hypothesis is that drugs tested on such platforms would better reflect and predict the outcome of the tests conducted on patients during the clinical trials at an earlier stage of the drug development process. The first organs-on-chips were described around 2010 by researchers recapitulating the liver, the kidney, the lung, or a combination of tumor, liver, and bone marrow cells in separate compartments, at microfluidic scales [18-21]. The origin of organs-on-chips is a combination of the sciences and technologies behind microfluidics and tissue engineering (Figure 1.4).

In microfluidics, channel geometries range from tens to hundreds of micrometers (about the size of a human hair or the thickness of a piece of paper) with amounts of fluid in the nanoliter scale [22]. At these geometries, the properties of fluids that we are familiar with from the macro world is drastically changed. For example, two liquids in a parallel flow will mostly mix due to diffusion as opposed to turbulence in larger structures $[23,24]$. The change in ratio between surface area and volume is another difference that significantly affects the properties in microfluidic devices. This means that the proportion of fluid that is in direct contact with the channel walls is increased so that adsorption and absorption can occur much faster and efficiently compared to larger channel diameters. An example of microfluidics from the human body is the blood capillaries where oxygen and nutrients and other molecules rapidly and efficiently are transferred from the blood stream to the tissues. Besides being relevant for mimicking biological structures, microfluidics is also advantageous due to the decreasing cost when only 
requiring minute amounts of samples, cells, drugs or other important but expensive factors. Microfluidics are also known as lab-on-a-chip devices, implying that several functions such as the preparation, the chemical reaction, and the analysis normally performed as separate steps in a laboratory, can instead be performed on a single microdevice. The first use of such a device can be dated back to the capillary electrophoresis on a chip described in 1992 by Andreas Manz et al. (Figure 1.4) [25]. The origin of microfluidics can be attributed to several technological achievements including sensors and actuators, microfabrication, and the manipulation of fluids in microanalytical methods [22]. The first electrical sensors appeared at the end of the 19th century with one of the first invention being the thermostat made by Warren Johnson. Microfabrication methods for microelectronics sprung out of the invention of the integrated circuit by Jack Kilby in 1958, which

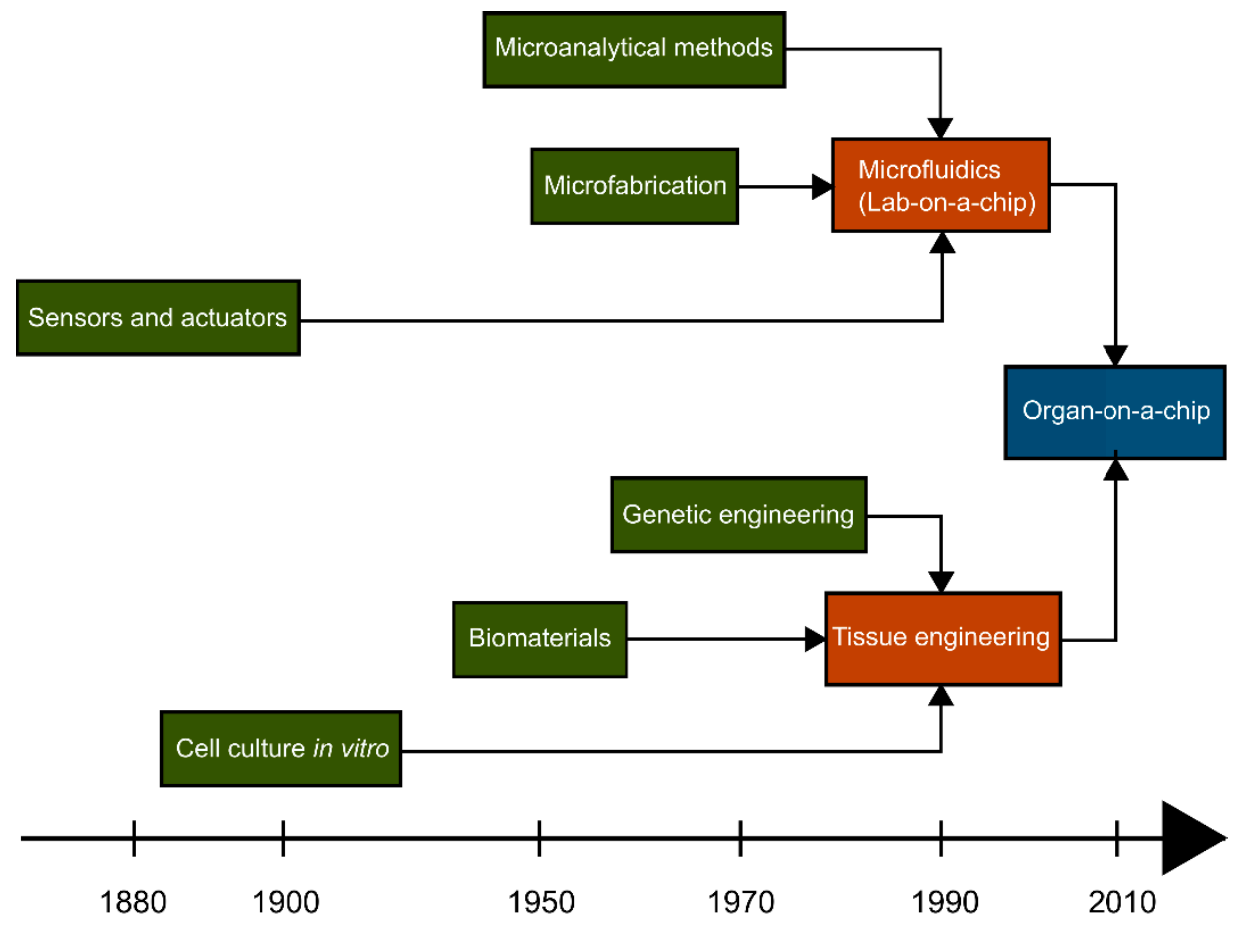

Figure 1.4 The concept of organs-on-chips (blue) emerged around the year 2010 by the combination of microfluidics and tissue engineering (orange) which in turn are scientific fields supported by several technological discoveries during the $20^{\text {th }}$ century, of which some are included on this timeline (green). 
was also the year when one of the first microanalytical methods for electrophoresis was described by Stellan Hjertén [26,27].

In tissue engineering, the purpose is to create functional structures formed by cells and supporting scaffolds (or biomaterials) for the repair or replacement of damaged tissue, and is intended for clinical use (Figure 1.4) [28]. The challenge of tissue engineering, as with tissue transplantation in general, is to engraft the tissue into a new biological context without causing severe immune responses. To avoid such effects, the materials used, both cells and scaffolds, must be compatible with the in vivo environment of the patient. Tissue engineering involves the techniques of in vitro cell culture, biomaterials, and genetic engineering. The first use of cell cultures was reported by Ross Harrison in 1907 who managed to maintain and grow isolated nerve cells from frogs in vitro [29]. Biomaterials are components that can improve a biological function in vivo. During the second world war, the military surgeon Harold Ridley observed that shatters of glass and acrylic substances that penetrated the eyes of pilots often had insignificant effects on the tissue's reaction to the material (unless in contact with sensitive or mobile parts of the eye) [30]. This discovery led to the first intraocular lens being implanted in 1949 in order to cure cataract. A third scientific discovery and technology that is important for tissue engineering and cell cultures in general is the genetic engineering of cell material. The reprogramming of mature cells into stem cells, known as induced pluripotent stem cells (iPSCs), and subsequent differentiation to a specific cell type offers the opportunity to tailor patient specific tissues that potentially can become a valuable cell source for engineered tissues and transplantation. The induced pluripotent stem cells were first presented in 2006 by Kazutoshi Takahashi and Shinya Yamanaka [31]. The recombinant DNA technology, which initiated the field of genetic engineering however, can be traced back to the 1970s when David Jackson et al. successfully inserted foreign DNA segments into the bacteria Escherichia coli [32].

The merger of tissue engineering and microfluidics into organs-on-chips makes it possible to create new and imporved types of cell 
environments. These environments can more accurately recapitulate the dynamics and 3D architectures of the tissues and organs in our bodies compared to standard 2D cell cultures where the cells grow flat on a plastic surface. This way, the cells reaction to drug substances would ideally be more comparable to the in vivo trials on animals and humans. The challenge however, is to increase the complexity of the models without losing too much of the handling simplicity which will affect the cost and the reproducibility of the model.

\subsection{Aim of the thesis}

The aim of this thesis has been to implement perfusion and 3D cell culture environments with the intention to create cell-based models for drug testing. For this purpose, perfused microdevices have been used as bioreactors for culturing and analyzing cells.

The conducted research show how 3D cardiac cell spheroids can be seeded into two types of perfused microbioreactors and analyzed using non-invasive video- or image-based methods (Paper I-II) or fluorescent high content imaging (Paper II). It also introduces a modular electroosmotic pump that can produce high enough flow rates to affect the morphology of endothelial cells (Paper III). Furthermore, a hydrogel suitable for providing support to hepatocytes in a perfused microbioreactor is demonstrated (Paper IV). Finally, a theoretical approach for conceiving organ-on-a-chip prototypes based on the requirements of the final user is outlined using conceptual design methodology (Paper V). 


\section{The cell and the cell environment}

With the aim to recreate the functions of the cells in vitro, the design of a cell culture model such as an organ-on-a-chip should consider both the cell itself its native environment. In this chapter, some important cell functions and activities - for the thesis and for cell culture models in general - are briefly described and related to their importance for in vitro models. Furthermore, the origin of the cell, the communication between cells, and the spatial and dynamic in vivo environment are illustrated.

\subsection{Cell function}

The cell is an active unit found in any organism and its function is to a large extent dependent on the cell type. Some functions are mechanical like the contraction and relaxation of the cardiomyocytes in the heart, or the transportation of oxygen from the lung to the tissues by erythrocytes in the blood. Other functions are biochemical, for example the insulin production by beta-cells in the pancreas, the electrochemical signals via neurons, and the production of albumin and metabolizing enzymes by hepatocytes in the liver. A few cells, i.e. the rods and cones in the retina of the eye, can transform light into electrical signals. Most cells have in common that they need to be able to communicate with each other and to respond to biochemical and mechanical stimuli from the environment. Furthermore, a healthy cell can undergo apoptosis - or programmed cell death - in case of cellular stress or other environmental cues [33]. If any of these functions are compromised, there is a risk to develop a disease or a disability. It is therefore of vital importance that the cells in a cell culture model express and perform their functions in a way that closely reflects its native in vivo state for a reliable assessment about the impact of a drug.

\subsubsection{Contraction and relaxation of cardiomyocytes}

The contraction of cardiomyocytes is initiated when a change in the local cell environment causes a depolarization of the cell, leading to the opening of calcium ion channels and influx of calcium ions to the cell (Figure 2.1a) [34]. The calcium concentration is further amplified via a 


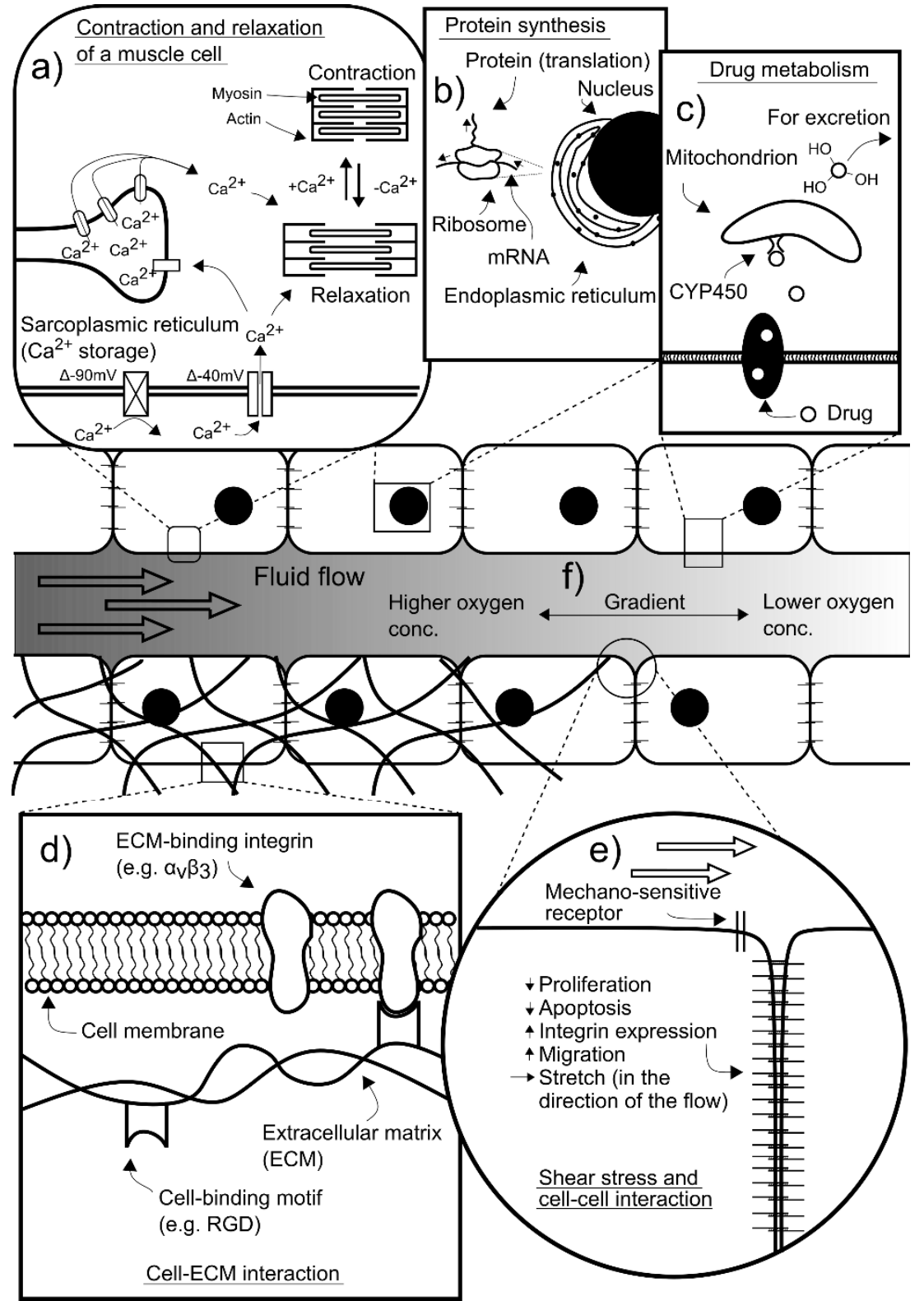

Figure 2.1. An illustration of the dynamic in vivo environment. Important cell functions include a) the contraction of myocytes, b) protein synthesis, c) drug metabolism, and the interaction with the ECM. Cells are affected by e) shear stress and f) gradients arising within the tissues. Note that some cell functions are specific to the cell type and not necessarily occurring in the same tissue as depicted in this drawing. 
calcium-induced calcium release from the sarcoplasmic reticulum, which serves as a calcium ion storage. The contraction occurs due to calcium ions binding to troponin causing a conformation change that frees actin from tropomyosin, in order for myosin to push actin towards the center of the cell. During repolarization of the cell, the concentration of intracellular calcium is decreased with a subsequent relaxation of the muscle cell as calcium is dissociated from troponin.

Potential targets to change the beating rhythm are therefore the receptors on the cell membrane that cause the change in membrane potential. Besides calcium receptors, also sodium- and potassium receptors are highly involved in the contraction-relaxation cycle. Examples of receptor antagonists are verapamil that blocks calcium receptors, quinidine that blocks sodium receptors, and amiodarone that blocks potassium receptors, to reduce and stabilize the beating rate and are drugs used to treat cardiac arrhythmia [35].

\subsubsection{Protein synthesis}

Cells synthesize proteins with a variety of effects, either on the cell itself, on cells of the local environment, or on cells elsewhere in the body. For example, serum albumin is produced by hepatocytes in the liver and is the most common protein in the blood where it binds and transports ions and molecules such as fatty acids and drugs as well as regulating the osmotic balance of the blood vessels [36]. A protein such as albumin is synthesized in a process called translation (Figure 2.1b). Translation occurs after transcription of genes in the DNA into mRNA when ribosomes translate the nucleotide sequences into amino acids and assemble them into proteins [37].

During pharmaceutical development, it is important that the potential drug does not unintentionally interfere with the cells natural synthesis of proteins or other biochemical substances which can lead to side effects. In a cell culture model, the expression of key proteins and enzymes are ideally continuously monitored to detect changes in cell function. 


\subsubsection{Drug metabolism}

Metabolism is the conversion of compounds for use as energy, building blocks, or for detoxification and excretion (drug metabolism). The main responsible organ for xenobiotics - i.e. drugs or other chemical substances that do not belong to the body naturally - is the liver, and its task is to restructure and modify the chemical, so it can be excreted [38]. Drug metabolism occur within the hepatocytes and is often divided into three phases [38]. During phase 1, enzymes on the mitochondrion and endoplasmic reticulum belonging to the cytochrome P450 (CYP450) family of hemoproteins modify the xenobiotic by introducing reactive groups to the compound by oxidation, reduction, or hydrolysis (Figure 2.1c). During phase 2 and phase 3, the reactive groups are conjugated with compounds that neutralize the drug and facilitates its excretion.

From a drug development perspective, it is crucial that the drug candidate can be excreted from the body after a certain time, and that the drug metabolites are not toxic. The cells in a cell culture model should therefore express the relevant enzymes involved in drug metabolism at physiological levels to mimic the clearance and potential toxic effects a drug might display in vivo.

\subsection{Cell-cell communication and co-cultures}

Cells communicate through biochemical and mechanical signals. Biochemical signals are molecules produced and released by a cell that affect either themselves (intracrine and autocrine signals), the cells of the local environment (juxtacrine and paracrine signaling), or cells in a distant environment (endocrine signaling) [39]. Mechanical signals are the effects of exerted forces on a cell, produced by a neighboring cell. Signals can also be categorized as homotypic or heterotypic, acting either on the same cell type as where it was produced or on a different cell type. Examples of homotypic signals are the calcium signaling between cardiomyocytes that initiates the contraction of the muscle fiber, or the release of neurotransmitters between the axons and dendrites in neurons carrying electrical signals through the body. Heterotypic signals include the endocrine interplay between the liver and the kidneys in the endocrine renin-angiotensin system that regulate the blood pressure [40]. All these signals influence the cells proliferation, migration, 
differentiation, and apoptosis which will also significantly affect the function of the cells and ultimately the organ of which they are inhabiting. In the most simple cell culture models, one single cell type is plated and consequently only homotypic signals are present. To compensate for the lack of heterotypic signals, serum or conditioned medium containing an assortment of growth factors, proteins, amino acids, and metabolites that would otherwise be supplied by other cell types, can be added to the cell culture medium [41]. However, the use of such supplements is hampered by the inherent batch-to-batch variability in concentration of minor components that can affect cell growth and function, resulting in variations between the same cell culture model [42].

A different approach is to include relevant cell types, also known as co-culture cells or supporting cells, directly in the cell culture model to support the function of the target cell. For example, primary hepatocytes in co-culture with fibroblasts or liver sinusoidal cells have been shown to maintain viability and functionality over increased times spans $[43,44]$. Co-cultures of cells could therefore also be of interest for organson-chips and drug testing to improve stability and viability in long-term culture.

\subsection{The extracellular matrix}

Cellular communication is not only occurring between cells, but also between cells and the extracellular matrix (ECM). The ECM is present around and between cells in a complex assembly of proteins and polysaccharides excreted by cells of the local environment that gives the cells structural and chemical support. The elastic properties of the ECM protect the cells from physical damage and the water- and nutrient binding properties of the ECM maintain osmotic balance and provide chemical cues for survival and function. The most abundant components of the ECM are proteins such as collagen followed by elastins, fibronectins, laminins, and polysaccharides such as hyaluronan [45].

The composition of the ECM varies between different tissues, and regulate the stiffness of the cell support from an elastic modulus of a few hundred pascal $(\mathrm{Pa})$ in the brain and the liver, to several $\mathrm{MPa}$ in the 
tendon and cartilage [46]. The stiffness of the ECM is highly involved in cell function, migration, proliferation, apoptosis, and differentiation.

Cells express integrins on the surface of the membrane that binds to specific recognition sites on components of the ECM. For example, the amino acid sequence arginine-glycine-asparagine (RGD) is frequent in fibronectin to which cells that express integrins such as $\alpha_{\mathrm{v}} \beta_{3}$ and $\alpha_{5} \beta_{1}$ can bind (Figure 2.1d) [47]. RGD can be recreated in linear and cyclic forms with integrin specificity of the $\alpha v \beta_{3}$ towards the linear RGD while both $\alpha_{v} \beta_{3}$ and $\alpha_{5} \beta_{1}$ bind to the cyclic RGD [48]. Consequently, stronger cell adhesion occurs on cyclic RGD compared to linear RGD.

ECM derived components are frequently used to improve cell adhesion to surfaces in cell culture models. Furthermore, the retention of water makes these proteins and polysaccharides suitable to use as hydrogels to capture the cells in a 3D matrix and replicate the support function of the ECM in a cell culture model.

2.4. The role of shear stress and the dynamic in vivo environment

With every stroke, the heart supplies the body and its organs with blood through the cardiovascular system that acts as a transport route for nutrients, oxygen, waste removal, several cell types including immune cells, and other factors that are important for the cell and the cell environment. Fluids are recirculated through the blood system and through the lymphatic system i.e. the network for reabsorption of interstitial fluids surrounding the cells to the blood. Events within one organ, e.g. secretion of proteins or metabolism of chemicals, can therefore influence other organs in the system. For the design of drug compounds, how its effect on one organ is transferred to other organs must therefore be taken into consideration.

The flow of blood through the cardiovascular system also imposes mechanical forces on the cells by hydrostatic pressure and shear stress. These forces, referred to as hemodynamic forces, affect the cells and the cell environment, especially the endothelial cells covering the inside of the blood vessels [49]. Several of the endothelial cell's functions are influenced by the exerted shear stress that arise when the blood passes by the cells. The response from the cell depends on the type of flow in 
the local environment. While the blood flow is unidirectional and laminar in straight parts of the blood vessel, the flow profile is changed at curvatures, and at bifurcations where the blood vessels split up and branch out and becomes disturbed or alternating (oscillatory). The shear stress is the force acting on the wall of a channel during fluid motion. The laminar flow has a protective role on endothelial cells towards atherosclerosis - the narrowing of the blood vessel due to inflammation of the vessel wall - which occurs at locations with disturbed or alternating flow profiles [50]. The membrane of the endothelial cells is occupied by integrins and receptors that together with the lipid bilayer of the membrane itself, acts as a sensor for shear stress with signals that are transduced to affect intracellular signaling pathways and gene expression [49]. The results are endothelial cells with decreased proliferative capabilities (decreased growth rate), less prone to undergo apoptosis, increased integrin expression, and a more active migration (Figure 2.1e). Furthermore, if the shear stress is high enough, the morphology of the endothelial cells nuclei become enlarged and less circular, and at laminar flow, also elongated and stretched out in the direction of the flow [51]. One important outcome of the morphological changes on endothelial cells is the decreased permeability of the blood vessel. For example, the high shear stress in the capillaries of the bloodbrain barrier reduces the passage of drug compounds from the blood vessels to the brain.

Movement of molecules, and dynamic and spatial changes within organs does not only occur due to the flow of blood. Other important aspects are the diffusion and osmosis between and within cells and tissues. Moreover, cell metabolism also affects the local environment by consuming nutrients and oxygen. Such events can lead to the formation of concentration gradients. One example is the oxygen gradient present in the liver (Figure 2.1f) [16]. The liver is supplied with blood from the body via the hepatic portal vein (low oxygen concentration) and the hepatic artery (high oxygen concentration) that move towards the central vein located in the middle of the liver lobule. Along this route of about $500 \mu \mathrm{m}$, the concentration of oxygen is decreasing because it is being consumed by the cells, and has led to a specialization of the hepatocytes depending on where in the gradient they are located, 
commonly referred to as liver zonation. For example, most of the albumin and bile is formed in the relatively oxygen-rich zone close to the portal vein while drug metabolism is enhanced at the more oxygendepleted zone close to the central vein $[16,52]$.

\subsection{The difference between cells in $2 \mathrm{D}$ and cells in $3 \mathrm{D}$}

All cells have a polarity, i.e. one arbitrary part of the cell is at least to some extent different from another part. The polarity arises due to spatial differences of the cells and temporal changes in the native environment. When removing a cell from its natural habitat to a cell culture plate in vitro, much of this polarity is lost [53]. Cells in this type of cell culture model grow flat on the substrate (in 2D) and receive nutrients, oxygen, and other chemical cues from one side (from above) while the other side is attached to the cell culture plate. Consequently, there will be a relatively small difference between each cell in the $2 \mathrm{D}$ culture. The state in vivo is the complete opposite. Due to the neighboring cells and the surrounding ECM, each cell can adhere and spread out in all three dimensions. In such a conformation, the polarity of the cell is considerably larger compared to its $2 \mathrm{D}$ in vitro counterpart. However, the effect of cell polarity on an individual level is relatively small when compared to an aggregate of cells. Here, the polarity is increased due to concentration gradients between cells close to the nutrient-rich environment at the periphery of the aggregate and cells in the less nutritious core. Moreover, cell polarity also emerges in mixtures of different cell types (co-cultures) due to a variation of cell signals acting on the cells.

\subsection{Cell types and cell lines for in vitro models}

All the cells in one individual (except for the gametes and the microbes) contain the exact same genome but differ significantly in morphology and function [54]. The cells can therefore be classified into cell types based on morphology and function, e.g. the cardiomyocytes of the heart, the hepatocytes of of the liver, and the endothelial cells forming the inside of the blood vessel wall. Primary cells are cells that are removed from its native environment and transferred to a cell culture platform and are highly functional with physiological expression levels of 


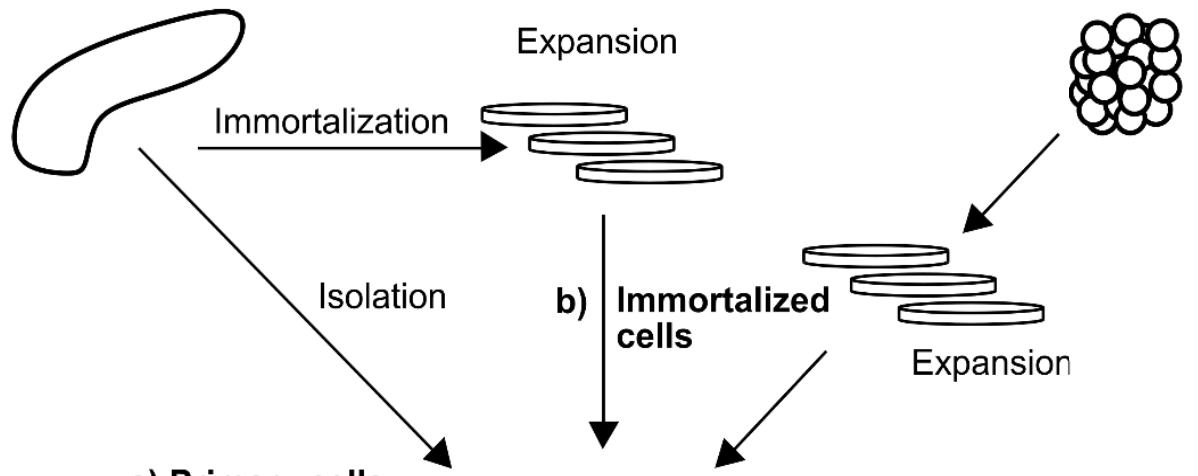

a) Primary cells

c) Embryonic stem cell derived cells

Differentiation

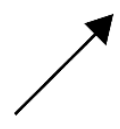

Cell culture model

d) Induced pluripotent stem cell derived cells

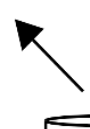

Differentiation

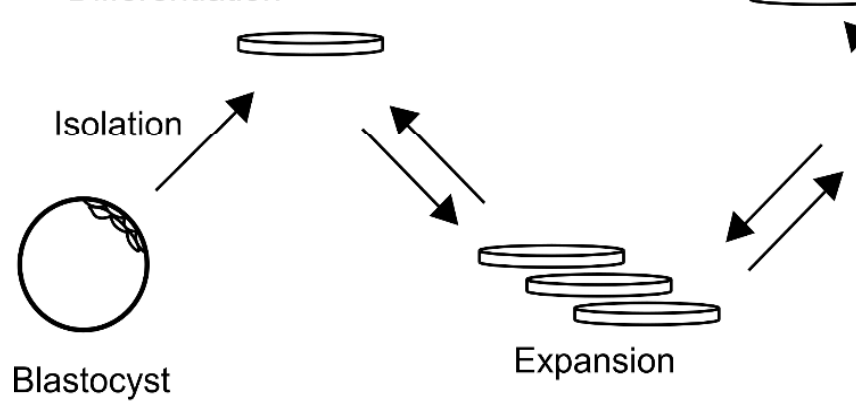

Any organ

Figure 2.2 The origin of the cells used in cell culture models. a) Primary cells are obtained by isolating cells from a specific organ. b) Immortalized cells originate either from genetic modification of primary cells or isolation of proliferative tumor cells. c) Embryonic stem cell derived cells are the products of differentiated cells isolated from the blastocyst of the early embryo. d) Induced pluripotent stem cell derived cells are cells that have been isolated from any organ, reprogrammed to stem cells, and differentiated to a specific cell type.

proteins and metabolic activity (Figure 2.2) [55]. The primary cells are often considered to be the golden standard for creating in vitro cell culture models. However, a decline in functional activity can be 
observed over time, starting immediately after removal from the in vivo environment. Furthermore, the availability of primary cells is low, especially cells of a human origin, and as they often have restricted proliferative capabilities or only maintain their functions over a certain number of cell divisions, there are limitations to large scale drug testing with cells from the same source. Alternatively, cell lines - a subpopulation of cells derived from a common parental cell - can be used and include immortalized cell lines and stem cell derived cell lines. Immortalized cell lines, either isolated from cancer tissues or primary cells genetically engineered to undergo indefinite cell division, can be used indefinitely with continuous proliferation without apoptosis. The disadvantage of immortalized cell lines is that they do not reflect the full palette of functional activities observed in primary cells. Furthermore, the possible consequence of genetic changes after numerous cell divisions over an extended time period, can make the cell significantly different from the original parent cell.

With the progress in stem cell technology, a potential unlimited source of cell material of the same origin with physiologically relevant functions and protein expression could be available. Stem cells are either isolated from the blastocyst of the early embryo - embryonic stem cells - or obtained by reprogramming adult cells into stem cells - induced pluripotent stem cells - and can theoretically undergo unlimited cell division. The stem cell can then be differentiated into any functional cell by the addition of chemical factors. Consequently, in vitro cell culture platforms representing different organs can be created using cells of the same origin and identical genome. The differentiated cell can also contain a genome with the mutation causing the disease in order to create a cell culture model for drug testing that represent the disease it is intended to cure. 


\section{The organ-on-a-chip}

\subsection{Principle design features}

The organ-on-a-chip is a continuous bioreactor with cells residing in a cell culture chamber that is connected to a perfusion system via adjacent channels (Figure 4.1a). The perfusion is supplied from a source operating either off-chip connected via tubing, or directly on the chip, or is integrated in the chip. The cell culture medium is either continuously perfused through the device with constant renewal of fresh medium, recirculated from outlet to inlet, or alternating back and forth. Analysis of the cells can be carried out in situ or by off-line analysis. Finally, the device is possible to sterilize to avoid contamination and compatible with standard incubator conditions (normally $37^{\circ} \mathrm{C}, 5 \% \mathrm{CO}_{2}, 95 \%$ humidity).

\subsection{Pumps for perfusion}

The perfusion of cell culture medium through the organ-on-a-chip is essential for both mechanical and biochemical reasons. The flow induces shear forces on the cells, altering their morphology and functional activity. It also keeps the environment rich in nutrients, oxygen, and other key factors for cell functionality, as well as removing and diluting toxic waste substances produced by the cells. While the character of the flow profile and velocity of the fluid is application-specific, common traits of an ideal pump for microfluidic cell cultures include (1) the ability to drive and manipulate tiny amounts of fluids at a range of velocities, (2) a limited dead-volume, i.e. the volume of the fluid not directly contributing to the cell environment, (3) the pump and all connectors should be easy to secure tightly and keep sterile, (4) the pump does not require extensive use of external equipment, (5) involve a limited number of connections and tubing, and (6) is individually addressable if several pumps are used in parallel.

Positive displacement pumps such as syringe- and peristaltic pumps are frequently used for their simplicity and availability (Figure 3.1b). These pumps are easy to maintain sterile by using disposable syringes and tubing and can provide high flow rates. While both pumps 


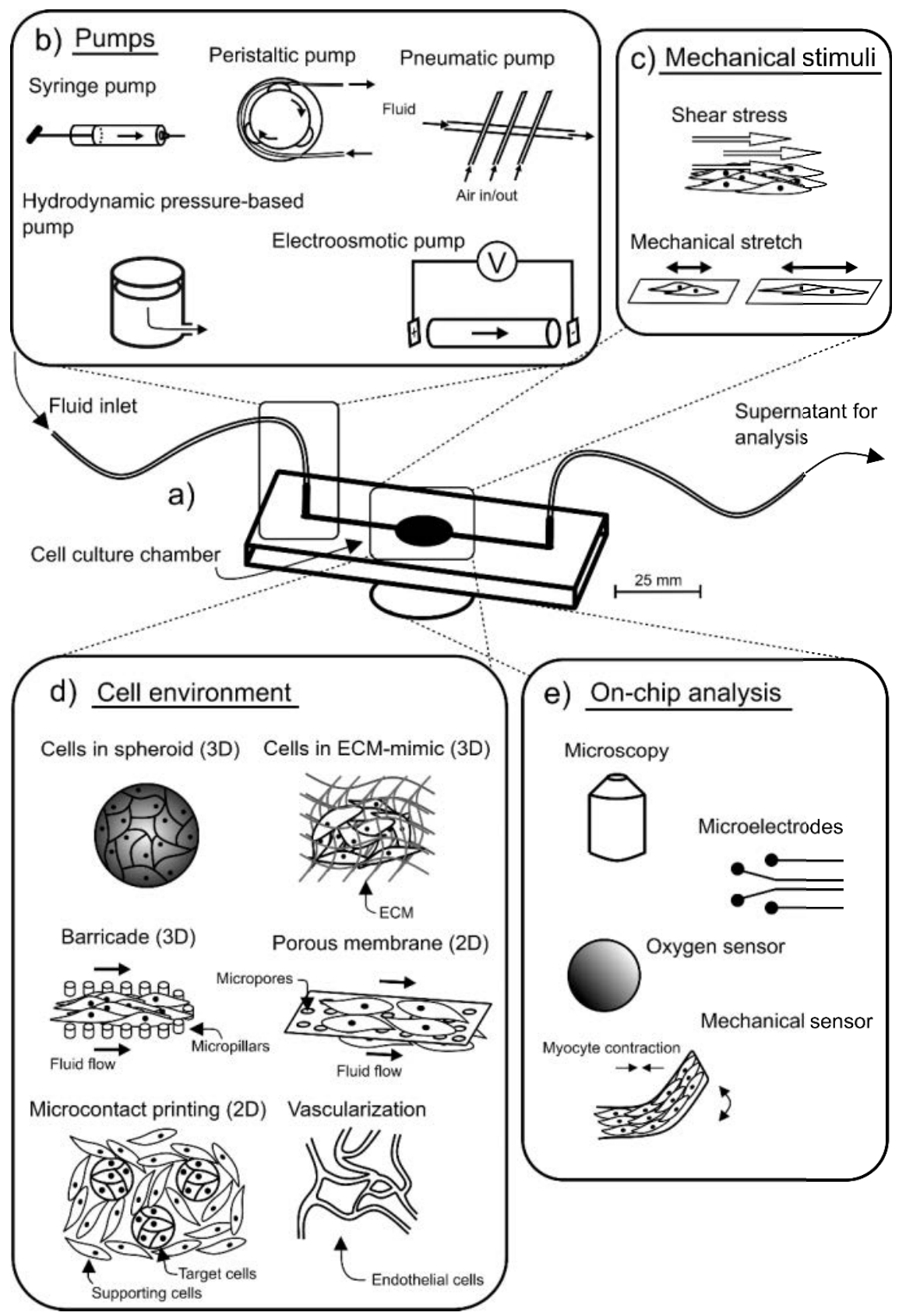

Figure 3.1 The basic functions of a) the organ-on-a-chip with examples of $b$ ) pumps used for perfusion of cell culture medium, c) types of mechanical stimuli of cells, d) how cells can be arranged within the cell culture chamber, and d) methods for analysis of the cells. 
can alternate the flow back and forth, the peristaltic pump can also recirculate the flow in a loop. The major drawback of these pumps is the dead volume that appear due to the size of the syringe or the tubing that potentially can become very large compared to the volume of the device. Furthermore, the increased number of tubing during scale-out (parallelization) rapidly becomes a demanding challenge for high throughput applications. One approach to limit the amount of auxiliary equipment is to divide the perfusion from one pump into several channels, or from two syringes into a concentration gradient generator [56].

A significantly lower dead volume is required when using a pneumatic pump, especially if integrated into the device, to provide a recirculating perfusion. Microfabricated valves, known as Quakevalves, use elastomers intrinsic flexible properties in order to close a channel by an applied pressure in a pneumatic chamber from above [57]. With three valves in series, a net-flow in one direction can be achieved. These types of pumps have been used to provide dynamic flow and shear stress in multi-compartment organs-on-chips where cells of different origins can be cultured in the same fluidic circuit $[58,59]$. The major drawback, as with the syringe and peristaltic pumps, is the number of tubing required to operate several devices in parallel. However, this can be limited by using the same pneumatic membrane channels to drive the flow through several parallel cell culture chambers [60].

To remove the need of connecting external tubing to the device, open reservoirs at both ends of a channel can serve as non-mechanical hydrodynamic pressure-based pumps. The pressure-drop due to different heights of liquid in the two reservoirs drives the flow through the channel. Depending on the cross-sectional area of the channel, the time for hydrostatic equilibrium between the two reservoirs varies, and the fluid velocity constantly decrease. Alternatively, a rocking platform can be used to periodically change the height of the reservoirs for an alternating flow (back and forth) through the device [61]. This approach is suitable when the flow profile is of less importance as the flow velocity will change continuously and, in case of alternating flow, intermittently become static. 
Another non-mechanical technique to drive a flow is to apply an electric field along the channel to induce a liquid motion by electroosmosis. These electroosmotic pumps (EOPs) have been used to provide very precise quantities of fluids at low velocities [62]. However, their use for cell culture applications is limited primarily because of the risk of cell lysis due to the applied electric field, the risk of electrolysis at the electrodes causing air bubbles to arise which can disturb the cells or the flow, and the inability of EOPs to operate at physiological salt concentrations. Nevertheless, Glawdel et al. created a microfluidic device for toxicity testing of cells which included a concentration gradient and with perfusion supplied by an externally connected EOP [63]. To be suitable for use in organs-on-chips, improvements in stability at high flow rates without damaging the cells by the applied electric field or introducing air bubbles in the device, would be crucial.

\subsection{The cell environment}

The cells in the tissues in vivo does not appear in a randomized distribution, but in spatially well-defined organizations. The interplay and communication between cells and between cells and the environment can be mimicked in organs-on-chips by design and engineering. The key features to recreate are the 3D environment of the tissues, the crosstalk between cells across tissue- and cell type-specific barriers, and the vascularization of tissues by endothelial cells.

\subsubsection{Mechanical stimuli of cells}

Mechanical stimuli are present in all organs and are induced by the shear forces of circulating fluids, and strain and compression within and between functional tissues. The shear stress on cells in organs-on-chips is a consequence of the perfusion through the device (Figure 3.1c). The magnitude of the shear force is controlled by the velocity of the fluid and the cross-sectional area of the cell culture chamber.

Seeding epithelial and endothelial cells on opposite sides flexible porous membranes that stretch due to an applied vacuum from adjacent channels, and produce a mechanical stress on the cells to replicate the breathing of a lung, have been shown to increase the transportation of nanoparticles from the alveolar (epithelial) side to the capillary 
(endothelial) channel [20,64]. Furthermore, differentiation of cardiac progenitor cells and pluripotent stem cells into cardiomyocytes might benefit from mechanical forces, as well as electrical stimuli, to improve contractile properties $[65,66]$.

\subsubsection{Cells in 3D spheroids}

When there is no mechanical substrate for the cells to attach to, some cells start to aggregate and from spheroids (Figure 3.1c). The size of a spheroid is about $100-300 \mu \mathrm{m}$ in diameter, i.e. a range from a few hundred to a few thousand of cells per cluster. From a physiological perspective, a cell spheroid provides cell-cell interactions in a 3D environment. Furthermore, a concentration gradient of oxygen and nutrients will emerge from the perimeter of the spheroid and inward towards the center. From an engineering perspective, spheroid cultures offer discrete entities with high cell densities which can facilitate cell seeding in microfluidic devices. Spheroids of immortalized cells, primary cells, and of stem cell derived origin have been used to enhance or prolong functional CYP-activity in hepatocytes which potentially better reflects the impact of a drug on hepatotoxicity, compared to 2D cultures [67-69]. Another example is the co-culture of primary brain endothelial cells, pericytes, and astrocytes that have been shown to selfassemble into spheroids with a defined spatial arrangement of astrocytes at the center, and pericytes and endothelial cells at the perimeter of the spheroid [70].

As the size of the spheroid increase (approximately $200-500 \mu \mathrm{m}$ in diameter), the cells of the core can appear necrotic, which have been explained by an insufficient supply of oxygen and nutrients, a decrease in $\mathrm{pH}$, and an inability to remove toxic waste products [71].

\subsubsection{Hydrogels to mimic the ECM for cell support}

Hydrogels consist of proteins or polymers in a network that can bind a large amount of water. The conventional methods of 2D culture on plastic or glass exploit the cells to hard substrates with elastic modulus in the GPa range while for most tissues in vivo, the elastic modulus is in the $\mathrm{kPa}$ range $[72,73]$. Proteins are often used to coat a surface to facilitate cell adhesion. This $2 \mathrm{D}$ approach can be made slightly more complex by 
embedding the cells in two layers of e.g. collagen in a so-called sandwich assay. Even such a minor change in the cell environment has been used to improve and prolong cell functionality [74]. However, the cells in the sandwich culture, although surrounded with proteins in 3D, are still mostly located in 2D. To acquire a complete 3D environment, the cells can be encapsulated in a hydrogel matrix (Figure 3.1d). Hydrogels are formed when polymers are crosslinked, which is done either chemically or physically. In chemically crosslinked hydrogels, the polymers are conjugated by covalent bonds with high mechanical and thermal stability, and a wide range of viscoelastic properties [75]. Hydrogels can e.g. be covalently crosslinked by click-reaction between thiols and methacrylated collagen [76] or methacrylated hyaluronic acid [77]. Physically crosslinked hydrogels rely on supramolecular connections such as electrostatic- or hydrophobic interactions, and hydrogen bonding. Properties of physically crosslinked hydrogels include shearthinning and self-healing behaviors [78]. Alginate is an example of a naturally occurring polymer, and can be obtained from seaweed, that is physically crosslinked into hydrogels by divalent ions such as $\mathrm{Ca}^{2+}$, and have been used for biomedical applications including drug delivery [79] and in 3D tissue cultures [80-82]. Another example of a physically crosslinked hydrogel is agarose which gel due to double-helices forming by hydrogen bonding between hydroxyl groups and entanglement of the polysaccharide chains of agarose [83], and has been used to encapsulate cells in 3D environments [84-86]. Several types of hydrogels have been used to support and encapsulate cells in a diverse variety of organ-on-a-chip applications including; natural hydrogels like alginate $[21,87]$, agarose [88,89], collagen [90,91], fibrinogen [92,93], and Matrigel [94,95]; synthetic polymer hydrogels based on poly(ethylene glycol) $[96,97]$ or poly(lactic-co-glycolic acid) $[98,99]$; and hybrids of natural and synthetic polymers [100,101].

In a viscous matrix such as a hydrogel, some key properties that are not present in a common fluidic medium need to be considered. The structural integrity of the hydrogel is achieved by crosslinking the polymers in a process that must not interfere with cell structures in a harmful way. The crosslinking should ideally be rapid to ensure a spatially even distribution of cells. For in vitro use, the hydrogel should 
be stable over the time course of the experiments, unless the cells themselves are able to produce sufficient amounts of extracellular matrix proteins over time to replace the hydrogel. Furthermore, the diffusion of, in particular large and charged molecules, through highly viscous materials is considerably slower compared to liquids [102]. Another important aspect is, if required for the assay, the adhesion of the cells to the polymers of the hydrogel. The integrins on the cell surface must be compatible with cell-binding motifs incorporated in the matrix, for cell attachment to occur. Some natural polymers have intrinsic recognition sites for cell integrins, e.g. collagen and fibrinogen, where the amino acid sequences glycine-phenylalanine-hydroproxyline-glycine-glutamatearginine (GFOGER) and arginine-glycine-aspartate (RGD) respectively, can anchor the cell integrins [47]. Alternatively, polymers can be grafted with cell-binding motifs for cell attachment prior to crosslinking of the polymers.

\subsubsection{Spatial localization and microstructures}

Cells are often spatially arranged within organs-on-chips, either by engineering physical support constructs such as barricades and membranes, or by chemically modifying parts of the surface of a substrate with a protein for attachment of a specific (target) cell and coculture with supporting cells in a fabrication process called microcontact printing (Figure 3.1d) [43,103]. Creating barricades, e.g. by photolithography and soft lithography (see Chapter 4), typically consisting of pillars or cavities, to form niches for cells, confines the cellular localization to certain areas of the device while perfusion of cell culture medium is supplied either through the compartment or from adjacent channels [56,104]. Cells are infused either as single cells, with a disadvantage of substantial waste of cells if the spacing between the pillars is too wide, or as clusters or on microcarriers for a quicker cell seeding $[105,106]$. Depending on the size and organization of the niches in the microfluidic channel, single cells or single cell clusters can be captured and cultured separately $[107,108]$.

Several cell types influence each other from adjacent tissues or form barriers in vivo where the cells on each side can be of various types and grow under different environmental conditions. Organs-on-chips have 
been created where cells are separated by a porous membrane with supply of cell culture medium on each side, similar to the Transwell inserts used for microtiter plates. By altering the culture conditions on each side of the membrane, e.g. by using different cell culture media, an applied shear stress, or creating an air-liquid interface, the organ-on-achip can replicate certain functional structures of the body. One example is the blood-brain barrier where shear stress and the co-culture of brain cells such as astrocytes, pericytes, and neurons, strengthen the endothelial barrier and decrease the permeability of molecules across the barrier [109-111]. Porous membranes in organs-on-chips have been used to recreate several additional tissues and barriers including the skin, the placenta, the gut, and the lung [20,112-114].

\subsubsection{Vascularization of 3D cultures}

Tissues are vascularized by capillaries with a selectively permeable barrier that supply the cells and the cell environment with oxygen and nutrients and remove metabolic waste products. The maximum distance between capillaries is approximately $200 \mu \mathrm{m}$ and the distance from a cell to a blood vessel is consequently up to $100 \mu \mathrm{m}$ [115]. Endothelial cells have the capability of spontaneous tube formation in vitro and can be used as an assay for determination of a substance or material's ability to promote or inhibit angiogenesis [116,117]. Moreover, the cells of the endothelium have an impact on e.g. the functional activity of cardiomyocytes by the release of endothelin-1 [118], and support hepatocyte function and stability in in vitro cultures [44]. On-chip vascularization have been constructed in microfluidic bioreactors and could be essential for replicating in vivo-like gradients and paracrine signaling of endothelial tissues [119-121]. The vascularization of tissue within organs-on-chips might become an essential feature to support cell viability and to mimic the complexity of the in vivo environment, especially for long-term cultures $[115,122]$.

\subsubsection{On-chip analysis}

All cell-based assays need to implement analysis methods to investigate the condition of the cells in the culture. Compared to static 2D cell cultures, the methods used in organs-on-chips are not necessarily very 
different. Both bright-field and fluorescence microscopy are used to analyze morphology, viability, or specific cell components (Figure 3.1e). Visual inspection of the channels and the cell culture chamber (not only the cells) become extra important in perfused microbioreactors as the cell seeding often is more complicated, and air bubbles inside the channels is a problem often associated with microfluidics. Cells in 3D are often more difficult to analyze visually compared to $2 \mathrm{D}$ cells. For example, a large population of cells in a spheroid is covered behind the cells at the outer perimeter. To overcome the issue of a sterically obstructed ocular pathway, microscopy techniques such as confocal fluorescence microscopy and multiphoton microscopy are used to see structures inside the cell aggregate [123]. Fluorescent techniques require the addition of fluorescent probes which over time can interfere with cell viability and cell function. As also applied in static 2D cultures, microelectrodes are non-invasive that can be integrated with organs-onchips to produce electrophysiological measurements on cell physiology on e.g. the beating properties of cardiomyocytes [124] or neuronal network activity [125], or by measuring the transendothelial- or transepithelial electrical resistance (TEER) over monolayers of cells [110,126]. Another non-invasive technique is to incorporate oxygen sensitive sensors to monitor concentration changes as it is used by the cells [127]. Furthermore, monitoring the contractions of cardiomyocytes can be performed on flexible mechanical sensors that cause an increased electrical resistance due to the bending of the sensor [128].

The perfusate from the organ-on-a-chip can be analyzed for biomarkers on the same principle as when conducted on cell culture medium from static cell cultures. However, with a continuously supplied supernatant from organs-on-chips, cell culture medium can be monitored online which could be of great benefit for analysis and control of the cell culture environment in long-term experiments [127,129]. 


\section{Methods}

In this chapter, some of the basic methods to design and construct organs-on-chips, and the main methods used in this thesis are explained and exemplified. Both theoretical backgrounds and practical procedures are described and discussed.

\subsection{Photolithography for master fabrication}

Photolithography is a technique used for microfabrication and has its origin in the production of structures for microelectronics and the manufacture of integrated circuits [22]. In photolithography, a substrate such as a silicon wafer is covered with a photoresist (Figure 4.1a). The photoresist is a highly viscous light-sensitive epoxy-based material and the thickness of the resist on the wafer is decided by spinning the wafer at a defined velocity and will determine the height of the subsequent microstructures. The height is proportional to the viscosity of the photoresist and inversely proportional to the velocity of the spinning wafer. With the photoresist uniformly covering the wafer at the desired thickness, the photoresist is exposed to high energy UV-light. The photoresist will become soluble or insoluble to a developer depending on if it is of a positive or a negative sort. To create the patterns in the photoresist, an opaque mask with transparent patterns is designed in a material such as quartz or plastic. Hence, the UV-light will pass through the transparent parts of the mask and solubilize (positive photoresist) or initiate the crosslinking (negative photoresist) of the photoresist. After exposure, the crosslinking is completed on a hot-plate (post-exposure bake) and the patterns developed using a developer that either removes the UV-exposed (positive) photoresist or remove the unexposed (negative) photoresist. The result of the photolithography process is a substrate with defined structures, also known as a master, with a resolution in the micrometer range [130]. These fabrication conditions give ample opportunities to design and fabricate structures that mimic the sizes and ratios found in vivo for organs-on-chips. 
a) Photolithography

Photoresist

Substrate

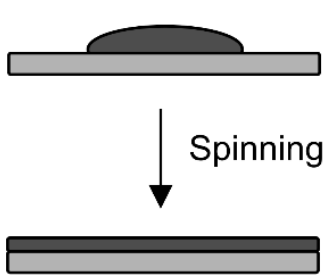

Height

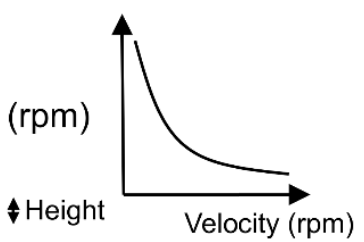

UV source
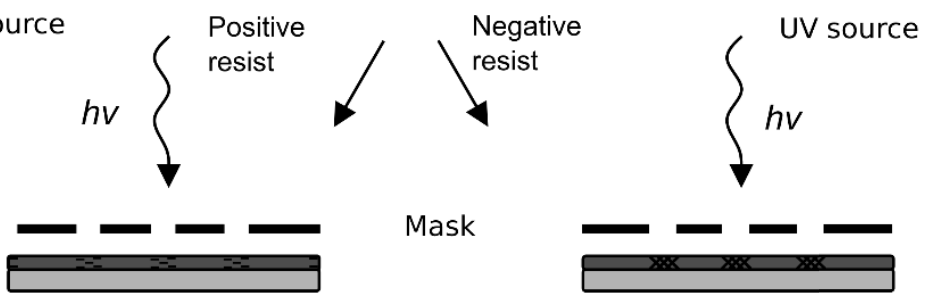

Mask
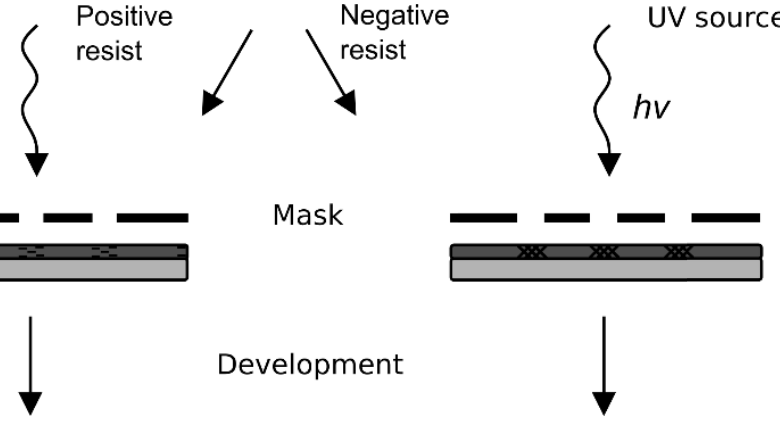

Development
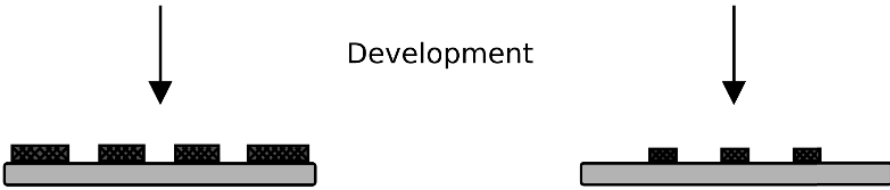

b) Soft lithography

Add PDMS
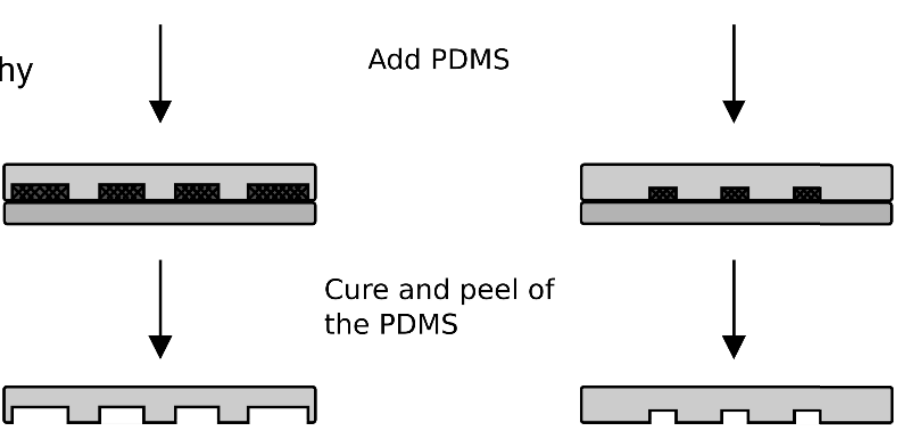

Cure and peel of the PDMS

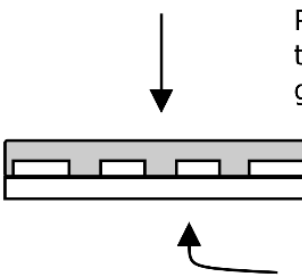

Plasma treat surfaces to bond PDMS to glass

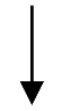

\section{Microfluidic devices}

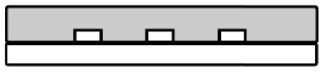

$\mathcal{4}$

Figure 4.1 Schematic overview of a) the fabrication of a master by photolithography and b) the subsequent soft lithography process for manufacturing a microfluidic device in PDMS bonded to a glass microscope slide. 


\subsection{Soft lithography for replica molding in PDMS}

Soft lithography is a method that involves techniques to produce and replicate structures using soft elastomeric materials. The most common material used by the organ-on-a-chip community for creating microbioreactors is polydimethylsiloxane (PDMS). This rubber-like material is very useful as microfluidic support because of its simplicity for replica molding on a master created by photolithography [131,132]. Furthermore, PDMS is transparent, permeable to gasses, and noncytotoxic. PDMS is created by mixing a prepolymer with a curing agent containing catalysts that accelerate the cross-linking. PDMS is a viscous liquid but possible to pour and can smoothly encapsulate structures and fill cavities on a master (Figure 4.1b). The curing of PDMS is usually completed after $2 \mathrm{~h}$ in $60^{\circ} \mathrm{C}$ and thereafter possible to peel off from the master. The microfluidic device is finalized by exposing the surface of the PDMS and the surface of a glass slide or coverslip with oxygen plasma for approximately 1 minute to create reactive hydroxyl groups for irreversible bonding. As PDMS is very hydrophobic, it is usually rinsed with ethanol followed by water or cell culture medium to remove air bubbles residing in the microstructures prior to seeding cells.

The wide adoption of PDMS in microfluidics and organ-on-a-chip applications can be correlated to its simple and relatively inexpensive fabrication procedure. However, serious drawbacks of the use of this material for microbioreactors have been shown and include 1) small (< $500 \mathrm{Da})$ hydrophobic molecules are absorbed into the bulk of PDMS leading to a possible misjudgment about the actual chemical concentration of e.g. a pharmaceutical candidate delivered to the cells, 2) if the PDMS is not properly cured or the ratio between prepolymer and curing is too high, un-crosslinked prepolymers can potentially contaminate the cell culture medium and possibly affect the cells, 3) the gas permeability is beneficial for oxygen and carbon dioxide, but also water vapor can pass through PDMS potentially leading to the formation of gas bubbles or a shift in salt concentration and $\mathrm{pH}$ [133]. The ideal material for soft lithography should of course not affect the cells or cause complications such as a change of the composition of the cell culture medium or the formation of air bubbles during cell culture. However, another important aspect for the commercial success of microfluidic 
devices is that the material should simplify the translation of a prototype into a product and enable high throughput manufacturing. Various materials including the UV-light curable off-stoichiometry thiol-ene (OSTE) and the Norland optical adhesive (NOA) have been suggested as alternatives to PDMS by combining easy prototyping and a high throughput manufacturing process $[134,135]$.

\subsection{Microfluidics to provide organs-on-chips with physiological dynamic conditions}

Microfluidics is the field of technology that is used to create, monitor and manipulate quantities of fluids around or below the nanoliter scale, in device geometries ranging from tens to hundreds of micrometers [22]. This scale is particularly interesting for biological applications as it covers a variety of sizes and surface-to-volume ratios that are found in vivo. For example, the vasculature of blood vessels, the proximal tubule structure of the nephrons in the kidney, and the barrier separating the blood from the brain have been replicated in microfluidic devices $[110,119,136]$. At these small scales, several fluidic behaviors are different from the macroscale. As the channel geometries become smaller, the surface-to-area ratio is increased making the effects of surface tension between the liquid and channel wall, and the liquid viscosity more dominant for the behavior of the flow. The type of flow in a channel can be described by the Reynolds number $(R e)$ which is the ratio between inertial and the viscous forces in the system:

$$
R e=\frac{\rho v L}{\mu}
$$

Where $\rho$ is the density of the fluid, $v$ is the velocity of the fluid, $L$ is the characteristic length or diameter of the channel, and $\mu$ is the dynamic viscosity of the fluid. Laminar flow occurs at $R e<2000$ and turbulent flow is observed at $R e>2000$ (Figure 4.2) [137]. A consequence of laminar flows is that mixing mainly occur due to diffusion compared to turbulent flow with turbulent mixing in larger systems [138]. An advantage of diffusion between two parallel flows is the possibility to create welldefined concentration gradients of e.g. pharmaceuticals or other 

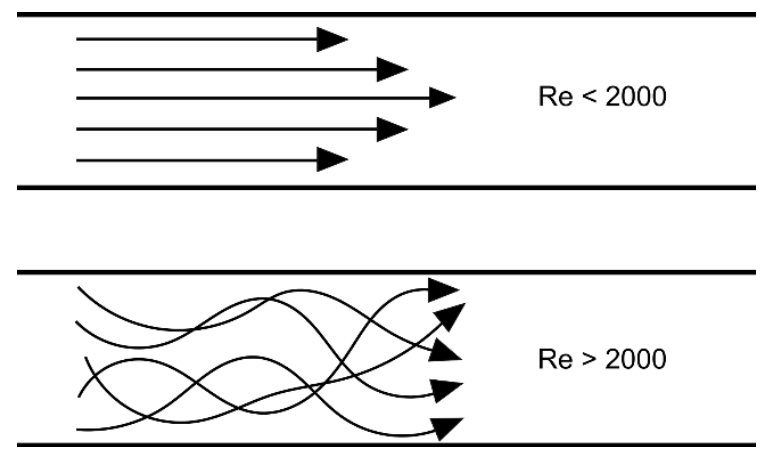

Figure 4.2 Flow patterns of a) laminar flow and

b) turbulent flow.

chemicals in a microbioreactor so that, instead of using several culture chambers with discrete concentrations, a continuous range of drugdoses can be tested in one experiment [139]. The drawback is that a proper mixing of nutrients, oxygen, and chemicals cannot be taken for granted. Several proposals on how to perform optimal mixing of fluids in microfluidic devices have therefore been suggested [140]. Another interesting aspect for biological applications of microfluidics is the increased shear stress, i.e. the force acting on the channel wall by the liquid, as the cross-sectional area of the channel is reduced (and the flow rate is constant). This force is also occurrent in vivo, especially affecting the endothelial cells forming the lumen of the blood vessels [49]. Microfluidic devices are often created with photolithography and etching procedures, and for cell culture devices, replica molding by soft lithography in the elastomer PDMS. Other methods for creating microfluidic devices include micromachining, micro injection molding, and hot embossing [141-143]. Moreover, with the improvement in resolution, $3 \mathrm{D}$ printing has emerged as a realistic option that can combine design flexibility and large-scale manufacturability. Recently, organ-on-a-chip devices have been constructed using 3D printing, both as an alternative to photolithography to produce masters and replica molding of PDMS, and as direct printing of cells encapsulated in a hydrogel matrix [144,145]. Microfluidic devices can also include methods to analyze and control the environment. Sensors and actuators can be integrated to monitor e.g. temperature, $\mathrm{pH}$, pressure, or cell density. Furthermore, the velocity of the fluidic flow can be controlled 
either actively by syringe pumps, peristaltic pumps, or electroosmotic pumps, or passively by e.g. capillary electrophoresis and hydrodynamic pressure. The combination of these micro-technologies into what is known as lab-on-a-chip devices have led to a range of commercial products for e.g. lab-ware products such as cytometry, electrophoresis, chromatography, and for consumer products such as monitoring blood glucose levels, pregnancy tests, and other means of point-of-care diagnostics [146,147].

One of the major advantages of microfluidics is the reduced need of expensive cell culture supplements such as serum, and the low quantity of pharmaceutical required. This can be especially interesting during the pharmaceutical development process when the amount of a drug substance is low due to the large-scale manufacturing not yet being implemented.

\subsection{Electroosmotic flow as an alternative to mechanically generated flow}

Electroosmosis is an effect instigated when an electric field is applied across a narrow liquid-filled channel. The effect is a fluid flow from one of the electrodes to the other and is triggered by the movement of ions at the solid-liquid interface - a phenomenon called electrophoresis - that drives the bulk of the liquid through the channel (Figure 4.3a). The direction of liquid motion depends on the surface charge of the channel wall and the direction of the applied electric field. For example, with a negative surface charge there will be a layer of positive ions from the solution at the interface between the liquid and the solid material, called the diffuse layer, that move towards the cathode (the negative electrode) and drive the bulk of the solution in the same direction. A criterion to generate this motion is that the channel diameter is very narrow, $<200$ 
a)

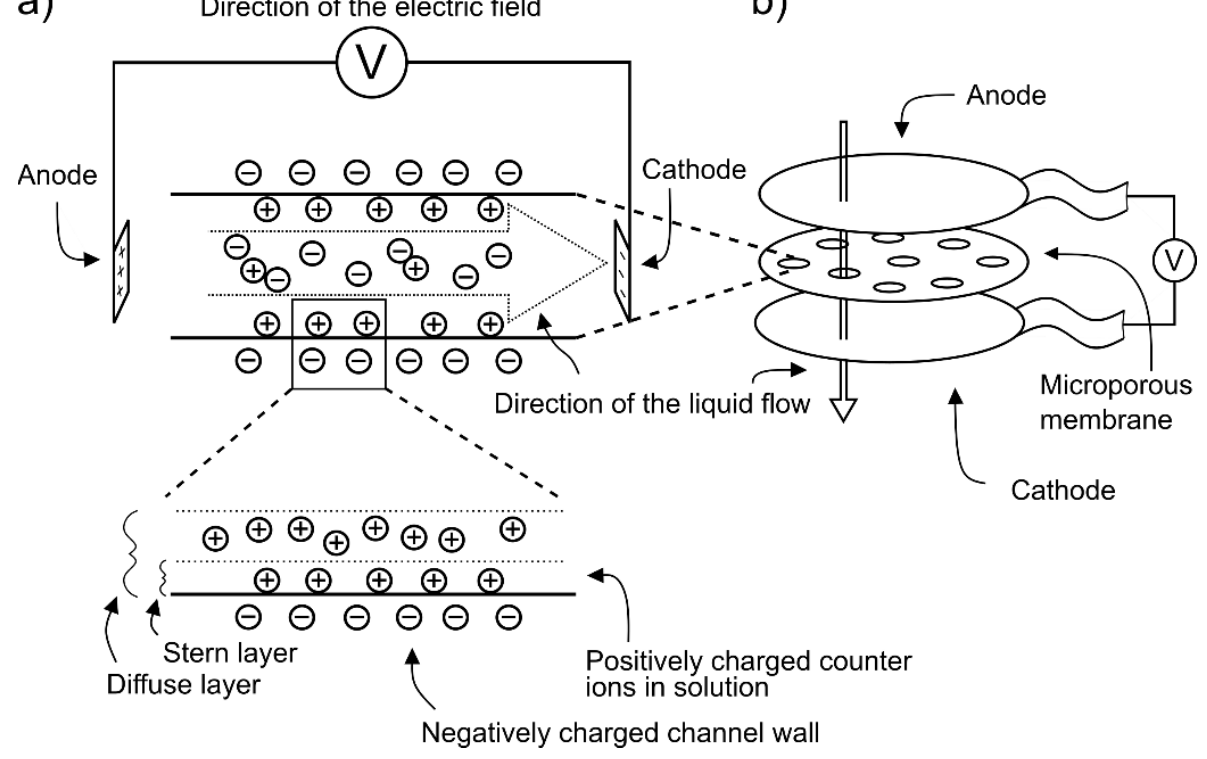

Figure 4.3 The principle of a) electroosmotic flow generated by the counter ions (in this case, positively charged) in the diffuse layer at the surface-liquid interface at the channel wall, and b) a general description of the construction of the electroosmotic pump used in Paper III, where the electroosmotic flow is generated in each pore of the membrane.

$\mu \mathrm{m}$ [148]. The flow velocity of the liquid $(v)$ is proportional to the relative dielectric constant of the solution $(\varepsilon r)$, the potential difference between the solid surface and the liquid (zeta-potential, $\zeta$ ), and the magnitude (and direction) of the applied electric field $(E)$, and inversely proportional to the viscosity of the liquid $(\eta)$ :

$$
v=\frac{\varepsilon_{0} \varepsilon_{r} \zeta E}{\eta}
$$

where $\varepsilon_{0}$ is the dielectric constant of vacuum. A material's permittivity is a measure on how it affects the strength of the electric field. The zetapotential is the potential difference at the interface right outside the charged counter ions at the channel wall, called the Stern layer. The flow velocity is a measure in length units per time units (meter/second), and is transformed to volumetric flow rate, which is a measure of the volume 
per time unit (liter/second), when multiplied by the cross-sectional area of the channel. Electroosmotic flow is the mechanism by which electroosmotic pumps (EOP) generate liquid flow. In Paper III, an EOP was operated to perfuse cell culture medium at high volumetric flow rates to produce shear stress on cells in a microchannel. The EOP consisted of a microporous membrane sandwiched between two electrodes created by a nylon textile coated with a conducting polymer (Figure 4.3b). Using this setup, each pore in the membrane represented one electroosmotic pump, making the volumetric flow rate proportional to the pore density. In this way, it was possible to achieve a physiologically relevant range of low rates and shear stress on cells in a cell culture device.

\subsection{Hydrogels to mimic the support function of ECM in vitro} A common approach to create a $3 \mathrm{D}$ environment for the cells in organson-chips is to mimic the ECM using scaffolds of proteins or polymers that form viscous hydrogels when binding liquids. The hydrogel acts as scaffolds to support the cells, and the viscosity of the material can in some cases be tuned to the stiffness of the cell's native tissue. Hydrogels are either injected into the device or formed in situ. For biological applications, the cells should ideally not be affected by the gelation procedure which is often the case during chemical crosslinking where initiators and catalysts are needed. However, a recent technique using the strain-promoted alkyne-azide 1,3-dipolar cycloaddition (SPAAC) has been suggested as a bioorthogonal method for hydrogel crosslinking [149-151]. A biorthogonal reaction implies that the reactants are noncytotoxic and do not interfere with integrins, receptors or other biological constituents found within the cell or on the cell membrane. In paper IV, hydrogels were used to capture hepatocytes in 3D matrices based on agarose, alginate or hyaluronan-poly(ethylene glycol) (HAPEG). The HA-PEG was crosslinked using SPAAC and could incorporate cell-binding motifs (RGD) for potential cell adhesion to the matrix. The principle of the crosslinking-method is outlined in Figure 4.4 where SPAAC is first used to graft an azide-coupled RGD to cycloalkyne-coupled hyaluronan (HA-BCN) and subsequently the HA- 
Cycloalkyne (BCN)
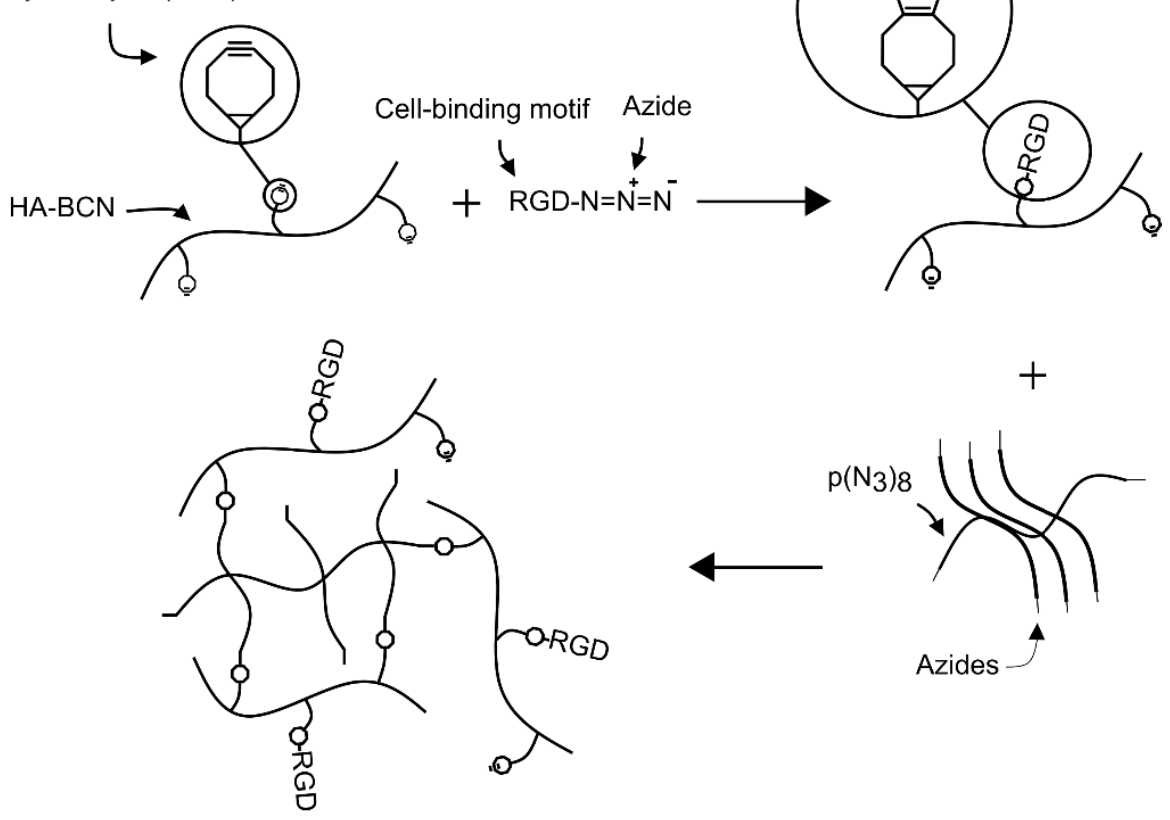

SPAAC crosslinked HA-PEG(RGD) hydrogel

Figure 4.4 The SPAAC crosslinked hydrogel used in Paper IV. RGD was first grafted to HA-BCN and subsequently to PEG to form hydrogels.

BCN-RGD complex reacts with azide-coupled PEG $\left(\mathrm{p}\left(\mathrm{N}_{3}\right)_{8}\right)$ using the same reaction, to form the hydrogel.

\subsection{Microbioreactors as generic organs-on-chips}

A bioreactor is a device where microorganisms are contained within an appropriate environment for cell survival, proliferation, and expression of functional activities. Four bioreactors at a microfluidic scale, or microbioreactors, have been used for cell culture during this thesis. The first was created with PDMS and glass using photolithography and soft lithography (Paper I). The other three were commercial products of a plastic polymer (Paper II-IV). The choice of microbioreactor was based on design criteria decided by the type of cells and the application of the proposed experiments. The principle design features of the fluidic devices are outlined in Figure 4.5. 
In Paper I, the task of the microbioreactor was to capture and maintain cardiomyocytes in spheroids with a diameter of 50-200 $\mu \mathrm{m}$. Each spheroid cluster should be individually monitored by video analysis which necessitated the spheroids to be cultured as discrete entities in an optically transparent device. The seeding of the clusters should be gentle as they could potentially be disrupted or damaged by harsh treatments, e.g. repeated pipetting. Finally, a bubble trap should be included to remove large air bubbles that can destroy cells and cell clusters, which often arises during perfusion culture at microscale. These design criteria were met by a PDMS device on a glass slide where ten cell culture chambers, or niches, were placed along a microfluidic channel (Figure 4.5a). Three drainage channels (too small for a spheroid to enter) were connected to each niche that were joined in a second adjacent channel with a separate outlet. The main channel of the device had separate inlets for cell culture medium and cardiac spheroids, an outlet for cell culture medium, and a port for a bubble trap consisting of a thin PDMS membrane with a vacuum applied from the outside by a syringe to remove air bubbles before the cell culture niches. Before the spheroids were introduced, the outlet of the main channel was closed and the outlet of the adjacent channel was opened to direct the cell culture medium through the niches. Spheroids were seeded by sedimentation through a pipette tip into the main channel via the designated inlet and were guided to the niches via the perfusion of cell culture media. Finally, the outlet of the main channel was opened, the outlet of the adjacent channel was closed, and a syringe pump was started to perfuse the bioreactor with cell culture medium with or without drug supplements.

With the microbioreactor design used in Paper I, cardiac spheroids were successfully introduced and monitored individually. However, for high-throughput applications, several parallel channels, or more niches in each channel would be required. Such experimental demands would require full automation of the pre-treatment of the chip and the cell seeding to be considered feasible. Moreover, the use of PDMS as a polymer in cell culture applications has been challenged, as stated previously. Therefore, a plastic microbioreactor was used in Paper II. 


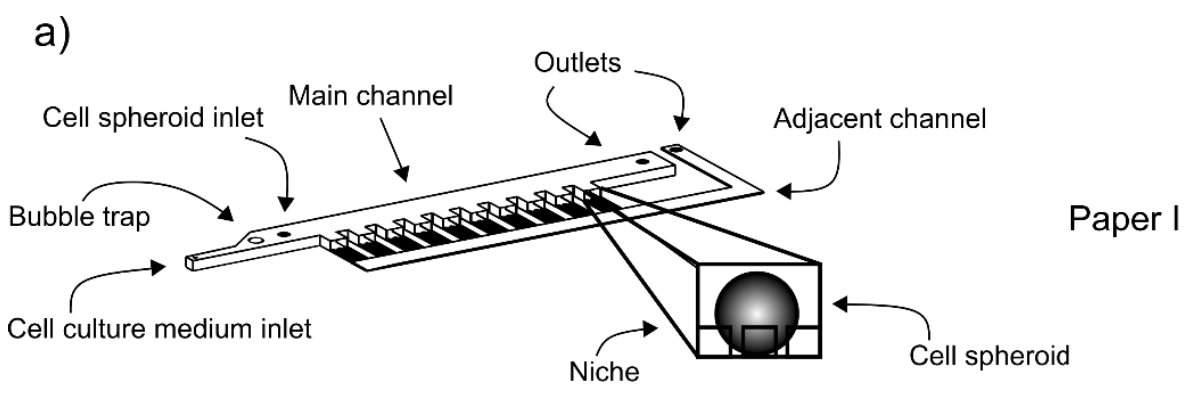

b)

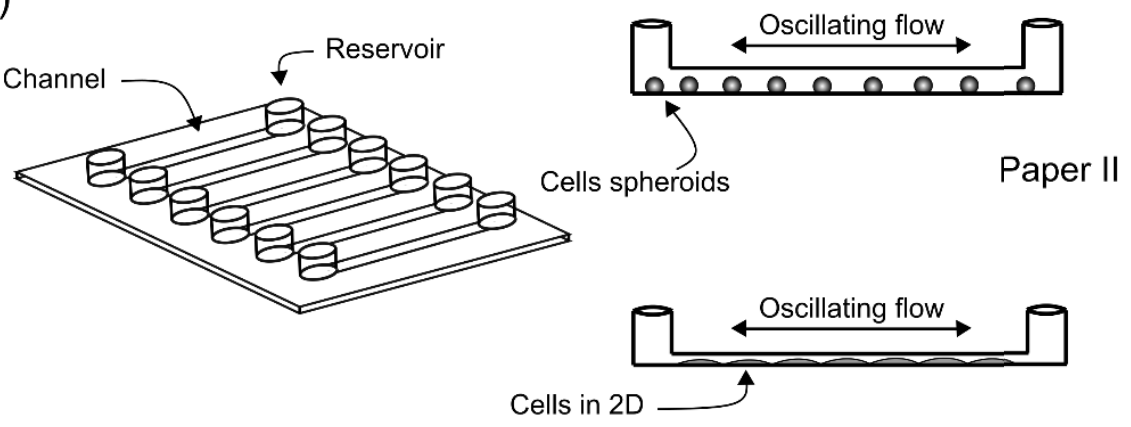

Paper III

C)

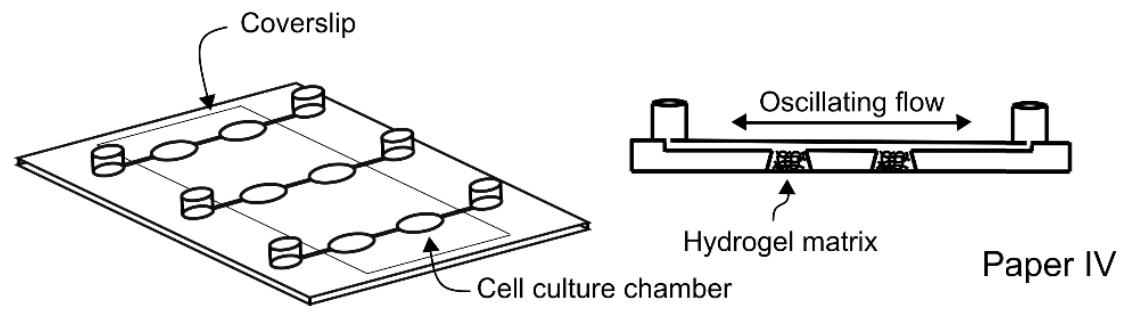

Figure 4.5 Microbioreactors used in a) Paper I, b) Paper II and Paper II, and c) Paper IV.

The design criteria were otherwise similar to the previous device with the exception that the setup should allow parallelization of several devices so that at least six drug conditions could be achieved simultaneously. For these experiments, a device containing six parallel channels with reservoirs on each side was used (Figure 4.5b). The 
surfaces of the channels were coated with laminin to allow the spheroids to attach to the bottom of the channels to ensure that the clustered remained inside the device during at least $48 \mathrm{~h}$ of culture. Perfusion of cell culture medium was produced by fixing the devices on a motorized rocking table to allow flow driven back and forth by gravity.

The experiments in Paper III required a microbioreactor where it was possible to produce high shear stress on 2D cells attached to a surface. Again, the device should be optically transparent to allow continuous monitoring by microscopy throughout the cell culture experiments. The shear inside a channel increases as the dimensions of the cross-sectional area decreases (if the flow velocity can be maintained). On the other hand, as a channel becomes smaller, the cell seeding density must be increased to rapidly obtain a confluent cell layer. Furthermore, the pressure a pump must be able to overcome to produce a flow is increased. After initial experiments, a microbioreactor with the same principal design as the one used in Paper II, except for a reduced channel height and width, was considered suitable from both pump performance perspectives and cell handling procedures (Figure 4.5b).

Paper IV describes a setup for cells entrapped in a hydrogel for up to 13 days with sampling and exchange of cell culture medium every second day. A common issue when handling hydrogels, especially at relatively low viscosities, is that manual pipetting easily interferes with the material causing the destruction of the matrix. The use of standard microtiter plates was therefore ruled out as cell culture medium was to be changed several times over the experiment. Instead, a microbioreactor design as outlined in Figure 4.5c was used. One device consisted of three parallel channels with two consecutive cell culture chambers where hydrogels and cells were added to open wells before sealing the chambers with a coverslip. Cell culture medium was introduced via reservoirs connected to the wells by microchannels and oscillating perfusion through the device was enabled by mounting the device on a rocking platform. Such a design feature facilitated sampling and exchange of cell culture medium as no direct contact with the hydrogel was needed. However, several washing steps were required at each medium change to ensure sufficient replacement. 


\subsection{Cell culture assays}

In any type of cell culture model, there are methods to analyze the cells. Such assays can for example determine the number of total cells, the number of viable cells, and the number of dead cells in the culture. In this way, information about a drug's or a material's cytotoxic impact can be determined using the ratio of living cells, or dead cells, to the total number of cells. More sophisticated cell culture assays can also investigate the functional activities of the cells. In general, cell culture assays can be divided into two categories; 1) end-point assays, and 2) continuous non-invasive assays. End-point assays are more sensitive and are conducted at the end of the culture when a chemical is added, such as fluorescent antibodies or a tetrazolium salt that directly interfere with the cells, or the cells are lysed to collect intracellular biomarkers or DNA for gene expression analysis. The non-invasive assays do not interfere with the cells and can thus be performed repeatedly over the time-course of the cell culture. Examples of such assays are quantification of extracellular biomarkers, bright-field imaging and video analysis, and analysis of electrophysiological recordings.

\subsubsection{Live/Dead assay}

A live/dead assay consists of two chemicals, e.g. calcein-AM and ethidium homodimer-1, that distinguish living cells from dead cells [152]. Calcein-AM can permeate the cell membrane where it is converted into calcein by esterase enzymes inside living cells. When calcein is excited at $495 \mathrm{~nm}$, it emits light at $515 \mathrm{~nm}$ resulting in a green fluorescent light from the cell cytosol of living cells. Ethidium homodimer-1 can only enter the cell if the cell membrane is damaged which is typical for dead cells. Once inside the cell, ethidium homodimer- 1 binds to nucleic acids where upon its fluorescent activity is enhanced and emits light at $635 \mathrm{~nm}$ when excited at $495 \mathrm{~nm}$, resulting in red fluorescent light from dead cells.

\subsubsection{ELISA}

The enzyme-linked immunosorbent assay (ELISA) can be used to quantify biomarkers from cell culture supernatants. There are several 
types of ELISAs which all make use of the same basic principle of the specific recognition between an antigen and an antibody [153]. In paper IV, a sandwich ELISA was used to quantify the amount of albumin produced by hepatocytes in a liver-on-a-chip. In a sandwich ELISA, a capture antibody is immobilized on a substrate (typically a microtiter plate). When the sample is added, the capture antibody specifically binds to the antigen (i.e. the biomarker to be quantified). A second antibody with a conjugated enzyme is added that specifically binds to the antigen on a different epitope. Finally, a substrate is added that react with the enzyme on the second antibody which produces a color that is measurable. The absorbance of the color measured by a spectrometer correlates with the amount of biomarker in the cell culture supernatant.

\subsubsection{Image processing and image analysis of cell cultures}

The basic principle of image processing is that digital images are built up by pixels, each represented by a frequency giving it a specific color or, in case of greyscale images, a certain intensity between black and white. This means that it is possible to use normal mathematical operators to adjust the image for different types of analysis, such as counting cells or measuring the area of an object. It is also possible to enhance a picture to visually distinguish information that is normally hidden to the naked eye, or to suppress unwanted information. A fundamental procedure is to create a binary image by applying a threshold value to the image [154]. If the value of a pixel is below the threshold it is replaced by a black pixel (0), and if it is equal to, or greater than, the threshold it is replaced by a white pixel (1) (Figure 4.6a). Binary images can easily be interpreted by a computer to find, e.g. the number of white pixels within a segment surrounded by black pixels (area) or to determine the number of segments where white pixels are surrounded by black pixels (counting). In Figure 4.6a, two segments, both with an area of 2 pixels, are detected. Additional information to a digital image is the position of each pixel and sometimes also its length. The accuracy of the analysis is improved by increasing the resolution of the image, i.e. the number of pixels per area.

In Paper I, the beating frequency of cardiac spheroids was determined by analysis of recorded videos. This was done by an algorithm called 
a)

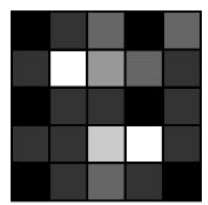

Gresyscale image (pixels)

\section{$\rightarrow$\begin{tabular}{|c|c|c|c|c|}
\hline 0 & 1 & 4 & 0 & 3 \\
\hline 1 & 10 & 6 & 4 & 1 \\
\hline 0 & 3 & 3 & 0 & 1 \\
\hline 1 & 1 & 8 & 10 & 2 \\
\hline 0 & 1 & 4 & 2 & 0 \\
\hline
\end{tabular}}

Behind each pixel is a value

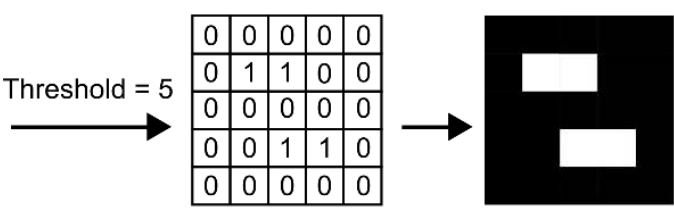

Binary image
Values after the threshold

b)
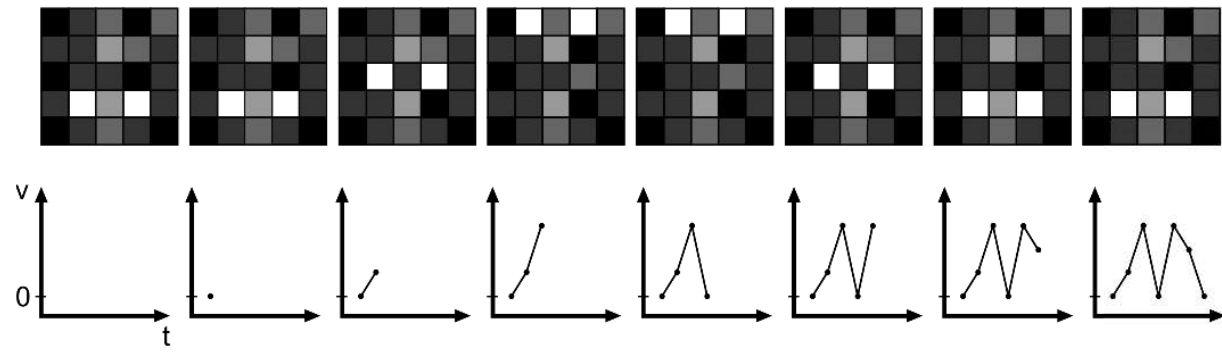

c)
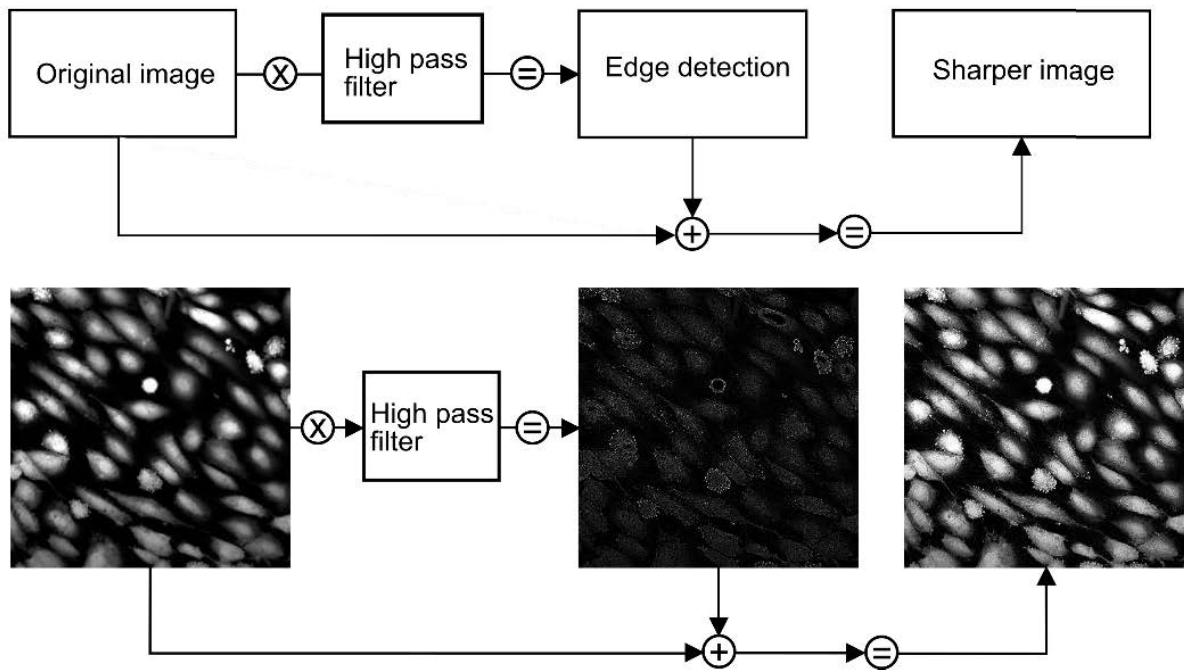

Figure 4.6 The basics of image processing. The principles of a) thresholding an image to obtain a binary image used e.g. for cell counting and area measurement b) Optical flow to determine the velocity of pixels in an image, and c) using a high pass filter to sharpen an image for edge detection. 
Optical flow which keeps track of all the pixels in the images and compares two adjacent videoframes to derive the pixel velocities. The sum of the velocities between two frames was plotted against time throughout the recording to visualize the movement of the cardiomyocytes in the video. The principle of the analysis method is shown in Figure $4.6 \mathrm{~b}$ where the movement of two white pixels is monitored over time. Note that, because there is no movement between frame number four and frame number five, two peaks are plotted in the graph. The peaks correspond to the contraction followed by the relaxation of a cardiac spheroid. The accuracy of this analysis is influenced by the resolution of the image, but also by the number of frames per second that the video camera can record. There is a possibility (or even probability) that the true peak of the turn from contraction to relaxation of the cardiac spheroid exists somewhere between two frames in the video recording. By increasing the number of frames per second, it would be possible to gain more information than the beating frequency of the spheroids, e.g. the velocity of a beating or the beating force.

A common method in image processing is to find the edge of an object which can be defined as a location where a rapid shift in pixel intensity occurs. To find these edges, the original image is passed through a high pass filter in an operation known as convolution. The result is an image with amplified frequencies of the pixels that were adjacent to significantly darker pixels. The sum of the new image and the original image produce an image that appears sharper than the original and can reveal previously concealed structures and information. It is important to note that no additional information is added to the image. Instead, already existing differences between pixels are enhanced. Fluorescent images of the cytosol of endothelial cells were convoluted with a high pass filter to reveal their confluency in Paper III. By such operation, it was possible to show how cells that had been exposed to shear stress covered more of the surface compared to cells that were culture at low shear. 


\subsection{Conceptual design methodology for product development}

When constructing a product, regardless if it's physical product like a cell culture model, a service product, or a virtual product like a software, there is always a range of design alternatives to consider. Some of the decisions are probably easier to make but there is a prominent risk that important aspects are overlooked due to previous standard-methods or misconceptions. In the end, all these decisions will, more or less, affect the design of the final product. This motivates a thorough design process where several alternatives are generated, screened and compared. To minimize the risk of bias concerning previous design solutions, alternatives should be judged based on their function instead of a physical attribute. To specify, a function concerns what a design feature should achieve while a physical attribute is about how it is achieved. As a more concrete example, for organs-on-chips, one plausible function is "shear stress" and its physical attribute can for example be "perfusion of cell culture medium using an electroosmotic pump".

The final design of a product is of course of importance for its success on the commercial market. However, the design is not only related its technical features. There are requirements from the user or customer that a product must comply with, such as the operability and handling, safety, compatibility with existing technology, laws and regulations, etc. As listed by Yetisen et al., the number one reason for which a startup company fails is that there is no market need [155]. As the authors further claim, a product should therefore be developed towards a known market need (market-driven) instead of first developing the product and then trying to find the market need (product-driven). This demands attention to the needs and requirements of the user during the design process.

To comply with these concerns, conceptual design methodology offers a framework based on graphs and tables where the focus of the design process is dedicated to the user's needs and requirements $[156,157]$. The first step of the process is to define the design mission and its constraints (Figure 4.7). As an appropriate example, a design mission can be to create a model where the effects of drug compounds can be monitored. The constraint can be that the model should be used in vitro 


\section{$\underline{\text { Task }}$}

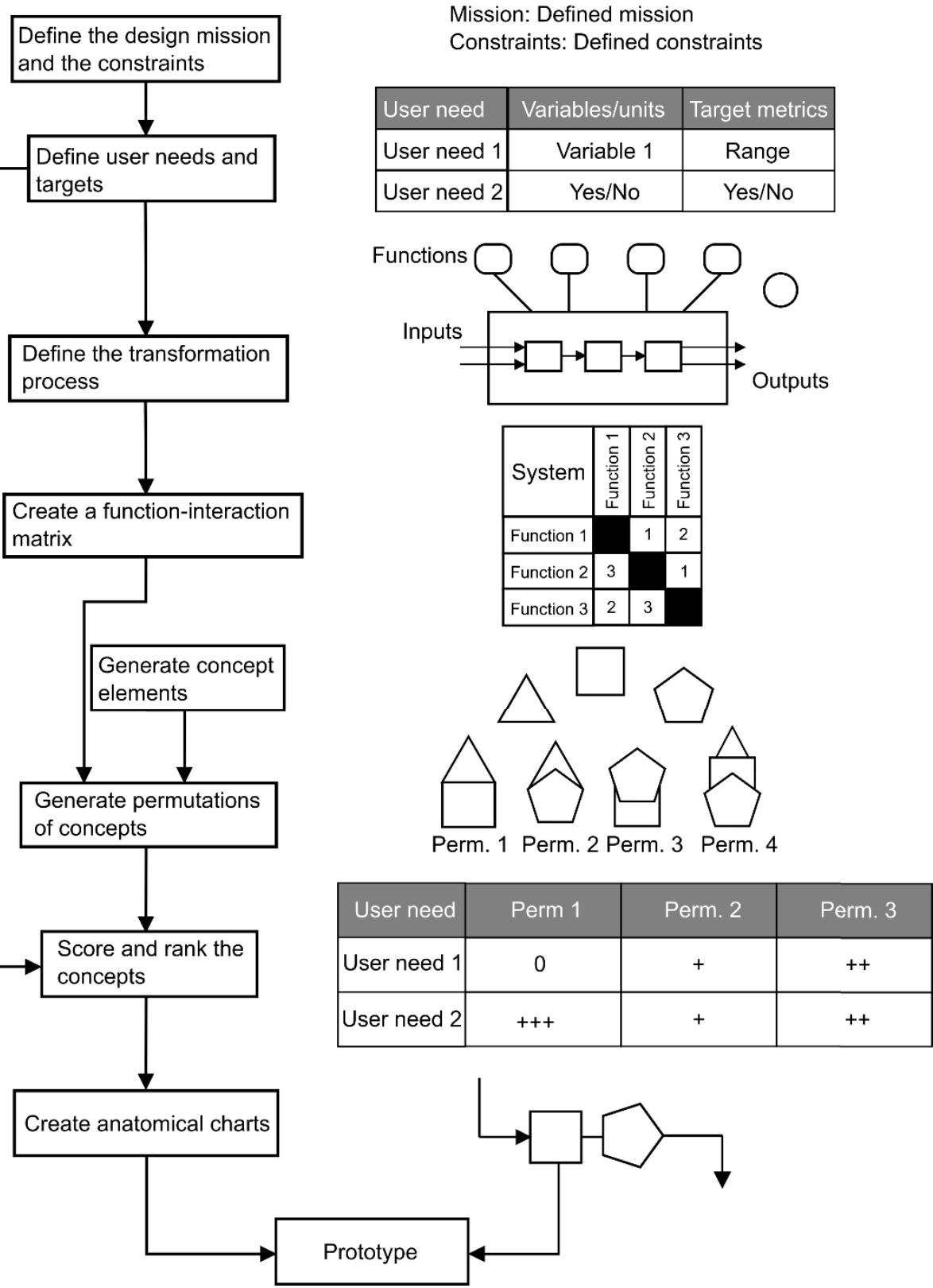

\section{Type of table or chart}

Mission: Defined mission

Constraints: Defined constraints

\begin{tabular}{|l|c|c|}
\hline User need & Variables/units & Target metrics \\
\hline User need 1 & Variable 1 & Range \\
\hline User need 2 & Yes/No & Yes/No \\
\hline
\end{tabular}

Perm. 1 Perm. 2 Perm. 3 Perm. 4

\begin{tabular}{|c|c|c|c|}
\hline User need & Perm 1 & Perm. 2 & Perm. 3 \\
\hline User need 1 & 0 & + & ++ \\
\hline User need 2 & +++ & + & ++ \\
\hline
\end{tabular}

Figure 4.7. A flowchart of the conceptual design methodology process. Following the definition of the design mission and the constraints, a set of charts and tables are used in a defined order to ensure a final prototype that fulfills the requirements of the user. 
using cells that are of relevance for the disease (i.e. not using animals or computer-based models). Next, the user's needs and requirements are specified as targets and defined in quantitative or qualitative values. With the need to produce shear stress in the cell culture model, a quantitative value would specify an acceptable range, e.g. $4-10 \mathrm{dyn} / \mathrm{cm}^{2}$.

The next step is to create a flow chart of the transformation process that include all the functions that are required to transform inputs to outputs. The functions for a cell culture model would include human systems (related to operators and people in contact with the product), biological systems (related to the requirements of the cells), technical systems (related to the physical requirements of the device), information systems (related to required software and processing of data etc.), management and goal systems (related to instructions, safety regulations etc.). Finally, there are considerations about an active environment (risk for infections, material variability etc.) that should be included. The relationship between functions are then investigated in a function-interaction matrix on how much they affect each other. For example, shear stress is likely to be highly affected by perfusion velocity and device geometries, but probably less dependent on what cells are being used. On the other hand, the shear stress might affect the cells and possibly also the device itself (connections and device geometries if an elastomer like PDMS is used).

During the next part of the design process, concept elements are generated that represent the listed functions in order to generate anatomical charts built up by combining the concept elements in different ways (called permutations). This results in several unique design alternatives that can be screened and scored towards how well they fulfill the user's needs and requirements. The design alternatives with the highest scores can then be further investigated and considered to be realized as prototypes. If properly performed, the conceptual design methodology should result in a design concept that fulfill the criteria of the user and, by that, have a relevant niche on the commercial market. In paper $\mathrm{V}$, conceptual design methodology was explained and applied on a liver-on-a-chip to investigate specific functions and to develop design alternatives. 


\section{Conclusion and further perspectives}

In general, the more parameters and variables that are accurately included in the model of a system, the better it will represent the system it is modelling. It is sound to assume that a complex model gives an improved representation of reality compared to a simple model. Yet, it does not necessarily imply that the complex model is better than the simple model. Intuitively, the more precisely an in vitro cell culture can merge the mechanical and biochemical cues of a dynamic and spatial in vivo environment, the more accurate predictions of the toxicity and efficacy of drug compounds in humans can be made. However, the challenge for organs-on-chips is not to make complex functional models. The challenge is to make complex usable models.

\subsection{Scaling down}

One of the advantages of miniaturization in microfluidics and lab-on-achip applications is the requirement of tiny amounts of materials. This is however also a challenge, especially for cell cultures. The cells need to stay within the microfluidic device, in some configurations be located in defined areas of a cell culture chamber, and, of course, be kept alive for a certain period of time. As the channel of a cell culture device become smaller, the concentration of the cell culture suspension used for cell seeding needs to increase. For example, the concentration of the primary endothelial cells used in Paper III was $15 \times 10^{6}$ cells $/ \mathrm{ml}$ to ensure a rapid confluency, which is a concentration several hundred times higher than the usually recommended seeding density for $2 \mathrm{D}$ cultures. The reason is the increased surface-to-volume ratio within the channel compared to the well of a microtiter plate. Likewise, 3D hydrogels demand a high cell density. The cell concentration for seeding cells in hydrogels used in Paper IV was $25 \times 10^{6} \mathrm{cells} / \mathrm{ml}$ which is a concentration about 30 times higher than the recommendations from the manufacturer of the iPS derived hepatocytes (hiPS-HEPs). Practically, it means that the cell pellet of hiPS-HEPs obtained after centrifugation was resuspended in $0.5 \mathrm{ml}$ instead of $15 \mathrm{ml}$ which expose the cells to a higher risk of taking damage by the manual pipetting procedures. This might be acceptable for immortalized cells and for proliferating primary cells, as potentially 
damaged cells at such high densities are flushed away and replaced by living cells after a couple of days. However, for non-dividing cells such as the hiPS-HEPs used in Paper IV, maintenance of living cells through the whole cell handling process, including the manual pipetting and seeding, is essential.

One way to overcome the issues of resuspending cells in high concentrations could be to use well-defined pre-aggregated cell spheroids as in Paper I-II. Furthermore, for cells in hydrogels, a crosslinking method such as SPAAC employed in Paper IV might be suitable to ensure a gentle cell seeding process.

\subsection{Scaling out}

Another advantage of miniaturization is the potential of increased throughput by parallelization of several devices on a small area. Such a scale-out is necessary for the pharmaceutical development process where microtiter plates with e.g. 96 and 384 individual wells are common cell culture formats. The challenge for several perfused microbioreactors is the need of tubing to supply perfusion of cell culture medium. The number of tubing become demanding from a user's perspective when devices are used in parallel. For example, the device created for Paper I required three tubing for perfusion of cell culture medium, one tubing for the bubble trap, as well as an inlet for the cell spheroids. Although only two of the perfusion tubing and the tubing for the bubble trap were actively used during the major part of the operation of the device, such a setup would be too difficult for manual handling in a higher throughput format.

A technique that does not require any tubing is the gravity induced perfusion used in Paper II and Paper IV. With the microbioreactor fixed on a motorized rocker, the perfusion conveniently oscillates back and forth through the device. However, volumetric flow rate is both limited and continuously changing within the device, restricting its use for wellcontrolled flow rates and high shear stress. The electroosmotic pump (EOP) applied to drive the perfusion in a microfluidic cell culture device in Paper III, on the other hand, could be placed immediately on top of the channel without the need of tubing, and supply relevant shear stress on endothelial cells. Further development of the flow stability, flow rate, 
and pump size could make the EOP a viable option for high throughput applications in microfluidics.

\subsection{Designing organs-on-chips}

Organs-on-chips are advanced cell culture models that require both cutting-edge engineering and well-defined cells and cell supplements. The merger of this into successful systems that are compatible for the pharmaceutical development process, puts a high demand on the design process with emphasis on throughput, reproducibility, and usability. Conceptual design methodology, as exemplified for the design of a liveron-a-chip in Paper V, could be a vital tool for thorough and more objective prototyping of organ-on-a-chips.

\subsection{Further perspectives}

Although cells have been employed to model the in vivo environment in a range of constellations, the concept of organs-on-chips is relatively new. Nevertheless, organ-on-a-chip devices have already started to emerge in commercialized formats [158]. Furthermore, several systems that connect organs-on-chips in series into multi-organs-on-chips, or humans-on-chips, have previously been demonstrated [21,129,159,160]. The purpose of a human-on-a-chip is to further mimic the pharmacodynamics and the pharmacokinetics of a drug. Implementing additional organs-on-chips in the same model would, of course, demand even more optimization of the design and function of each individual organ-on-a-chip. It also poses new challenges such as producing a common cell culture medium that is suitable for the entire model. However, with the incentives to make better pre-clinical trials and to decrease the use of animal experiments coming from academia, regulatory agencies, public organizations, and pharmaceutical industry, the challenges faced by the adoption of organs-on-a-chips into the pharmaceutical development process might very well be overcome, resulting in a faster process for more reliable and better suited pharmaceuticals. 


\section{Summary of the papers}

\section{Paper I}

Gunnar Bergström*, Jonas Christoffersson*, Kristin Schwanke, Robert Zweigerdt, and Carl-Fredrik Mandenius

Stem cell derived in vivo-like human cardiac bodies in a microfluidic device for toxicity testing by beating frequency imaging

Lab on a Chip, 2015, 15, 3242

The aim of Paper I was to show that spheroids of cardiomyocytes could be seeded into a microfluidic device for drug testing with beating frequency imaging as detection method. Due to concerns of damaging the spheroids by manual handling, the seeding of the cells should be as gentle as possible. Furthermore, neighboring spheroids tend to fuse which alter their beating frequency. Hence, the spheroids should be seeded in distinctly separated locations. A microbioreactor was created using photolithography and soft lithography where single spheroids could be seeded into separate niches. Videos of the spheroids were captured and analyzed using a custom made Matlab program that showed how the beating frequency is changed when exposed to three drugs at three concentrations. The results suggest that these cardiac spheroids can be used for drug testing in microfluidic bioreactors.

\section{Paper II}

Jonas Christoffersson, Florian Meier, Henning Kempf, Kristin Schwanke, Michelle Coffee, Mario Beilmann, Robert Zweigerdt, and Carl-Fredrik Mandenius

A cardiac cell outgrowth assay for evaluating drug compounds using a cardiac spheroid-on-a-chip device

Manuscript

The aim of Paper II was to quantify the outgrowth of cells from cardiac spheroids when seeded on laminin coated surfaces in a perfused microdevice, and determine if the number of cells outside the spheroids correlate with the exposure of a set of drugs. Bright-field imaging clearly showed a decrease or an increase of the number of cells outside the 
spheroids depending on the drug compound. For an objective quantification, the nuclei were stained with a fluorescent dye and analyzed by high content imaging. The visual inspection was partly confirmed and showed a decreased cell number when exposed to doxorubicin and endothelin-1, and an increased cell number when exposed to phenylephrine and amiodarone. The results indicate that the number of cells surrounding the cardiac spheroids can be used as a noninvasive qualitive assay by bright-field microscopy, or as an end-point assay by using fluorescence microscopy.

\section{Paper III}

Katarina Bengtsson*, Jonas Christoffersson*, Carl-Fredrik Mandenius, and Nathaniel D. Robinson

A clip-on electroosmotic pump for oscillating flow in microfluidic cell culture devices

Microfluidics and Nanofluidics, Accepted Manuscript, 2018

The aim of Paper III was to show that electroosmotic pumps (EOPs) can be an alternative to drive the perfusion through microfluidic cell culture devices. EOPs usually operate at low flow rates that are not physiologically relevant. By incorporating a flexible EOP into a syringe filter holder, it was easily integrated to the connections of fluidic microchannels. The pump was able to produce a shear stress of at least $5 \mathrm{dyn} / \mathrm{cm}^{2}$ for $48 \mathrm{~h}$ which affected the morphology of endothelial cells. The results demonstrate an EOP operating at high flow rates and its potential for use in microfluidic cell culture devices.

\section{Paper IV}

Jonas Christoffersson*, Christopher Aronsson*, Michael Jury, Robert Selegård, Daniel Aili, and Carl-Fredrik Mandenius

Bioorthogonally crosslinked hyaluronan-poly(ethylene glycol)-RGD hydrogels for supporting hepatic cells in a perfused liver-on-a-chip Submitted

The aim of Paper IV was to create a liver-on-a-chip using carcinoma cells (HepG2) and induced pluripotent stem cell derived cells (hiPS-HEPs) 
encapsulated in hydrogels. Cells were resuspended in hydrogels made of agarose, alginate, and hyaluronan-PEG were used and crosslinked in the wells of a microfluidic device. Furthermore, the hyaluronan-PEG hydrogel could be grafted with linear- or cyclic RGD amino sequences which are cell-binding motifs that the hepatocytes potentially can interact with. HepG2 cells were cultured for 9 days and formed viable spheroids in all hydrogels with the highest production of albumin and urea in alginate. After 13 days of culture of hiPS-HEPs in the hydrogels, the viability was visibly highest in hyaluronan-PEG hydrogels grafted with cyclic RGD, compared to the other hydrogels, which was also supported by a relatively high production of albumin. The results demonstrate a convenient liver-on-a-chip setup with an easy-to-use twocomponent hydrogel. Furthermore, including cell-binding motifs appears to be advantageous when culturing hiPS-HEPs in hydrogels.

\section{Paper V}

Jonas Christoffersson, Danny van Noort, and Carl-Fredrik Mandenius

Developing organ-on-a-chip concepts using bio-mechatronic design Methodology

Biofabrication, 2017, 9, 025023

The aim of Paper V was to show how conceptual design methodology can be used to generate organ-on-a-chip concepts. This method motivates a user-driven design approach with the attention on the requirements of the final user. A list of user needs was proposed for a liver-on-a-chip, and the design methodology was followed to demonstrate each step in the process resulting in a theoretical prototype fulfilling the requirements of the user. The approach is recommended as a part of the design process to create organs-on-a-chips with higher potential to reach the commercial market.

* These authors contributed equally to the paper 


\section{Acknowledgments}

To my supervisor Carl-Fredrik Mandenius for giving me the opportunity to work in your group. I have learned a lot during this time. My co-supervisor Danny van Noort for the good discussions and the updates about how science is conducted around the world.

Past and present members of The Division of Biotechnology: Robert Gustavsson, from Kiev to Pyeongchang, from fishing in liquid nitrogen to every perfect biskvi, I've enjoyed the time ever since you recommended me to apply for this position. Patricia Roch for the awesome idea of a beer competition that we are both losing. Also, for taking all my stuff so I know where to find it. Judit Randek, merci for all the late-evening chocolate. I sincerely wish you the best of luck in your lab work. Gunnar Bergström, for a fun fight to tame PDMS, around the clock, without ever giving up hope.

It's been a pleasure working with you all.

Katarina Bengtsson and Nate Robinson, for the work with your pump and for all the discussions about everything else.

Christopher Aronsson, Robert Selegård, and Daniel Aili, for your hydrogels and some sort of every-day collaboration.

Henning Kempf, Kristin Schwanke and the group of Robert Zweigerdt. I have really appreciated working with you and the opportunity to be working with your cells.

Florian Meier, for every encouraging TC with you and the collaboration we have had.

To all the people around IFM and Linköping University. Stefan Klintström and Forum Scientium. The glorious Kaffeklubben and everyone around at the daily 11.30 meetings in Zenit.

Special thanks for the times when outside the university, Mamma, Pappa, Måns, Pensionärs-Mickes Fanclub, Martin, Daniel, Andreas "Mugman" Skallberg, and Hannah. 


\section{References}

1. Hughes, J.P.; Rees, S.; Kalindjian, S.B.; Philpott, K.L. Principles of early drug discovery. Br. J. Pharmacol. 2011, 162, 1239-1249.

2. Bhatia, S.N.; Ingber, D.E. Microfluidic organs-on-chips. Nat. Biotechnol. 2014, 32, 760.

3. Langman, L.J.; Kapur, B.M. Toxicology: Then and now. Clin. Biochem. 2006, 39, 498-510.

4. Kim, J.H.; Scialli, A.R. Thalidomide: The tragedy of birth defects and the effective treatment of disease. Toxicol. Sci. 2011, 122, 1-6.

5. European Union. Regulation (ec) no 1223/2009 of the european parliament and of the council of 30 november 2009 on cosmetic products. Ojeu 1342/59. 2009.

6. US National Academy of Sciences. Toxicity testing in the 21st century: A vision and a strategy. The National Academies Press, 2007.

7. ICH Harmonised tripartite guideline. Safety pharmacology studies for human pharmaceuticals s7a. 2000.

8. European Union. Directive 2010/63/eu of the eurpean parliament and of the council of 22 september 2010 on the protection of animals used for scientific purposes. Ojeu 1 276/33. 2010.

9. Törnqvist, E.; Annas, A.; Granath, B.; Jalkesten, E.; Cotgreave, I.; Öberg, M. Strategic focus on $3 r$ principles reveals major reductions in the use of animals in pharmaceutical toxicity testing. PLoS One 2014, 9, e101638.

10. Hodgson, J. Admet-turning chemicals into drugs. Nat. Biotechnol. 2001, 19, 722.

11. Paul, S.M.; Mytelka, D.S.; Dunwiddie, C.T.; Persinger, C.C.; Munos, B.H.; Lindborg, S.R.; Schacht, A.L. How to improve r\&d productivity: The pharmaceutical industry's grand challenge. Nature Reviews Drug Discovery 2010, 9, 203.

12. U.S. Food and Drug Administration. The drug development process.

https://www.fda.gov/ForPatients/Approvals/Drugs/ucm 405622. htm (January 2018), 
13. Onakpoya, I.J.; Heneghan, C.J.; Aronson, J.K. Post-marketing withdrawal of 462 medicinal products because of adverse drug reactions: A systematic review of the world literature. BMC Med. 2016, 14, 10.

14. Marx, U.; Andersson, T.B.; Bahinski, A.; Beilmann, M.; Beken, S.; Cassee, F.R.; Cirit, M.; Daneshian, M.; Fitzpatrick, S.; Frey, O., et al. Biology-inspired microphysiological system approaches to solve the prediction dilemma of substance testing. ALTEX 2016, 33, 272-321.

15. Esch, E.W.; Bahinski, A.; Huh, D. Organs-on-chips at the frontiers of drug discovery. Nat Rev Drug Discov 2015, 14, 248-260.

16. Materne, E.M.; Tonevitsky, A.G.; Marx, U. Chip-based liver equivalents for toxicity testing-organotypicalness versus costefficient high throughput. Lab Chip 2013, 13, 3481-3495.

17. Shuler, M.L. Organ-, body- and disease-on-a-chip systems. Lab on a Chip 2017, 17, 2345-2346.

18. Lee, P.J.; Hung, P.J.; Lee, L.P. An artificial liver sinusoid with a microfluidic endothelial-like barrier for primary hepatocyte culture. Biotechnol. Bioeng. 2007, 97, 1340-1346.

19. Jang, K.-J.; Suh, K.-Y. A multi-layer microfluidic device for efficient culture and analysis of renal tubular cells. Lab on a Chip 2010, 10, 36-42.

20. Huh, D.; Matthews, B.D.; Mammoto, A.; Montoya-Zavala, M.; Hsin, H.Y.; Ingber, D.E. Reconstituting organ-level lung functions on a chip. Science 2010, 328, 1662.

21. Sung, J.H.; Shuler, M.L. A micro cell culture analog ([small micro]cca) with 3-d hydrogel culture of multiple cell lines to assess metabolism-dependent cytotoxicity of anti-cancer drugs. Lab on a Chip 2009, 9, 1385-1394.

22. Whitesides, G.M. The origins and the future of microfluidics. Nature 2006, 442, 368.

23. Dertinger, S.K.W.; Jiang, X.; Li, Z.; Murthy, V.N.; Whitesides, G.M. Gradients of substrate-bound laminin orient axonal specification of neurons. Proceedings of the National Academy of Sciences 2002, 99, 12542. 
24. Millet, L.J.; Stewart, M.E.; Nuzzo, R.G.; Gillette, M.U. Guiding neuron development with planar surface gradients of substrate cues deposited using microfluidic devices. Lab on a Chip 2010, 10, 1525-1535.

25. Manz, A.; Harrison, J.D.; Verpoorte, E.M.J.; Fettinger, J.C.; Paulus, A.; Lüdi, H.; Widmer, M.H. Planar chips technology for miniaturization and integration of separation techniques into monitoring system - capillary electrophoresis on a chip. J. Chromatogr. 1992, 593, 253-258.

26. Wong, H.; Iwai, H. The road to miniaturization. Physics World 2005, 18, 40 .

27. Hjertén, S. Free zone electrophoresis. Chromatogr. Rev. 1967, 9, 122-219.

28. Langer, R.; Vacanti, J.P. Tissue engineering. Science 1993, 260, 920.

29. Harrison, R.D. Observations of the living developing nerve fiber. The Anatomical Record 1907, 1, 116-128.

30. Apple, D.J.; Sims, J. Harold ridley and the invention of the intraocular lens. Surv. Ophthalmol. 1996, 40, 279-292.

31. Takahashi, K.; Yamanaka, S. Induction of pluripotent stem cells from mouse embryonic and adult fibroblast cultures by defined factors. Cell 2006, 126, 663-676.

32. Jackson, D.A.; Symons, R.H.; Berg, P. Biochemical method for inserting new genetic information into DNA of simian virus 40: Circular sv40 DNA molecules containing lambda phage genes and the galactose operon of escherichia coli. Proceedings of the National Academy of Sciences 1972, 69, 2904-2909.

33. Elmore, S. Apoptosis: A review of programmed cell death. Toxicol. Pathol. 2007, 35, 495-516.

34. Bers, D.M. Cardiac excitation-contraction coupling. Nature 2002, 415, 198.

35. Wichter, T.; Borggrefe, M.; Haverkamp, W.; Chen, X.; Breithardt, G. Efficacy of antiarrhythmic drugs in patients with arrhythmogenic right ventricular disease. Results in patients with inducible and noninducible ventricular tachycardia. Circulation 1992, 86, 29. 
36. Arroyo, V. Human serum albumin: Not just a plasma volume expander. Hepatology 2009, 50, 355-357.

37. Strachan, T.; Read, A.P. DNA structure and gene expression. In Human molecular genetics 3, 3rd ed.; Garland Science: 2004; pp 332.

38. Chang, S.Y.; Weber, E.J.; Ness, K.P.V.; Eaton, D.L.; Kelly, E.J. Liver and kidney on chips: Microphysiological models to understand transporter function. Clin. Pharmacol. Ther. 2016, 100, 464-478.

39. Freshney, R.I. Biology of cultured cells. In Culture of animal cells, 5th ed.; John Wiley \& Sons, Inc.: 2005; pp 31-42.

40. Griendling, K.K.; Murphy, T.J.; Alexander, R.W. Molecular biology of the renin-angiotensin system. Circulation 1993, 87, 1816.

41. Freshney, R.I. Cloning and selection. In Culture of animal cells, 5th ed.; John Wiley \& Sons, Inc.: 2005; pp 217-235.

42. Freshney, R.I. Serum-free media. In Culture of animal cells, 5th ed.; John Wiley \& Sons, Inc.: 2005; pp 129-143.

43. Khetani, S.R.; Bhatia, S.N. Microscale culture of human liver cells for drug development. Nat. Biotechnol. 2008, 26, 120-126.

44. Bale, S.S.; Golberg, I.; Jindal, R.; McCarty, W.J.; Luitje, M.; Hegde, M.; Bhushan, A.; Usta, O.B.; Yarmush, M.L. Long-term coculture strategies for primary hepatocytes and liver sinusoidal endothelial cells. Tissue Engineering Part C: Methods 2014, 21, 413422.

45. Frantz, C.; Stewart, K.M.; Weaver, V.M. The extracellular matrix at a glance. J. Cell Sci. 2010, 123, 4195.

46. Wells, R.G. The role of matrix stiffness in regulating cell behavior. Hepatology 2008, 47, 1394-1400.

47. Humphries, J.D.; Byron, A.; Humphries, M.J. Integrin ligands at a glance. J. Cell Sci. 2006, 119, 3901.

48. Wacker, B.K.; Alford, S.K.; Scott, E.A.; Das Thakur, M.; Longmore, G.D.; Elbert, D.L. Endothelial cell migration on rgdpeptide-containing peg hydrogels in the presence of sphingosine 1-phosphate. Biophys. J. 2008, 94, 273-285. 
49. Li, Y.-S.J.; Haga, J.H.; Chien, S. Molecular basis of the effects of shear stress on vascular endothelial cells. J. Biomech. 2005, 38, 1949-1971.

50. Malek, A.M.; Alper, S.L.; Izumo, S. Hemodynamic shear stress and its role in atherosclerosis. JAMA 1999, 282, 2035-2042.

51. Deguchi, S.; Maeda, K.; Ohashi, T.; Sato, M. Flow-induced hardening of endothelial nucleus as an intracellular stressbearing organelle. J. Biomech. 2005, 38, 1751-1759.

52. Oinonen, T.; Lindros, O.K. Zonation of hepatic cytochrome p-450 expression and regulation. Biochem. J. 1998, 329, 17-35.

53. Baker, B.M.; Chen, C.S. Deconstructing the third dimension how 3d culture microenvironments alter cellular cues. J. Cell Sci. 2012, 125, 3015.

54. Strachan, T.; Read, A.P. Structure and function of chromosomes. In Human molecular genetics 3, 3rd ed.; Garland Science: 2004; pp 33-58.

55. Katrin, Z.; Nora, F.; Georg, D.; Daniel, S.; Fanny, K. Cell sources for in vitro human liver cell culture models. Exp. Biol. Med. 2016, 241, 1684-1698.

56. Toh, Y.-C.; Lim, T.C.; Tai, D.; Xiao, G.; van Noort, D.; Yu, H. A microfluidic $3 \mathrm{~d}$ hepatocyte chip for drug toxicity testing. Lab on a Chip 2009, 9, 2026-2035.

57. Unger, M.A.; Chou, H.-P.; Thorsen, T.; Scherer, A.; Quake, S.R. Monolithic microfabricated valves and pumps by multilayer soft lithography. Science 2000, 288, 113.

58. Schimek, K.; Busek, M.; Brincker, S.; Groth, B.; Hoffmann, S.; Lauster, R.; Lindner, G.; Lorenz, A.; Menzel, U.; Sonntag, F., et al. Integrating biological vasculature into a multi-organ-chip microsystem. Lab on a Chip 2013, 13, 3588-3598.

59. Materne, E.-M.; Maschmeyer, I.; Lorenz, A.K.; Horland, R.; Schimek, K.M.S.; Busek, M.; Sonntag, F.; Lauster, R.; Marx, U. The multi-organ chip - a microfluidic platform for long-term multi-tissue coculture. 2015, e52526.

60. Wu, M.-H.; Huang, S.-B.; Cui, Z.; Cui, Z.; Lee, G.-B. Development of perfusion-based micro $3-\mathrm{d}$ cell culture platform and its 
application for high throughput drug testing. Sensors and Actuators B: Chemical 2008, 129, 231-240.

61. Esch, M.B.; Prot, J.M.; Wang, Y.I.; Miller, P.; Llamas-Vidales, J.R.; Naughton, B.A.; Applegate, D.R.; Shuler, M.L. Multi-cellular 3d human primary liver cell culture elevates metabolic activity under fluidic flow. Lab Chip 2015, 15, 2269-2277.

62. Chang, J.-Y.; Wang, S.; Allen, J.S.; Lee, S.H.; Chang, S.T.; Choi, Y.K.; Friedrich, C.; Choi, C.K. A novel miniature dynamic microfluidic cell culture platform using electro-osmosis diode pumping. Biomicrofluidics 2014, 8, 044116.

63. Glawdel, T.; Elbuken, C.; Lee, L.E.; Ren, C.L. Microfluidic system with integrated electroosmotic pumps, concentration gradient generator and fish cell line (rtgill-w1)--towards water toxicity testing. Lab Chip 2009, 9, 3243-3250.

64. Huh, D.; Leslie, D.C.; Matthews, B.D.; Fraser, J.P.; Jurek, S.; Hamilton, G.A.; Thorneloe, K.S.; McAlexander, M.A.; Ingber, D.E. A human disease model of drug toxicity-induced pulmonary edema in a lung-on-a-chip microdevice. Sci. Transl. Med. 2012, 4, 159 ra147.

65. Ruan, J.-L.; Tulloch, N.L.; Razumova, M.V.; Saiget, M.; Muskheli, V.; Pabon, L.; Reinecke, H.; Regnier, M.; Murry, C.E. Mechanical stress conditioning and electrical stimulation promote contractility and force maturation of induced pluripotent stem cell-derived human cardiac tissue. Circulation 2016, 134, 1557.

66. Geuss, L.R.; Suggs, L.J. Making cardiomyocytes: How mechanical stimulation can influence differentiation of pluripotent stem cells. Biotechnol. Prog. 2013, 29, 1089-1096.

67. Mueller, D.; Krämer, L.; Hoffmann, E.; Klein, S.; Noor, F. 3d organotypic heparg cultures as in vitro model for acute and repeated dose toxicity studies. Toxicol. In Vitro 2014, 28, 104-112.

68. Bell, C.C.; Lauschke, V.M.; Vorrink, S.U.; Palmgren, H.; Duffin, R.; Andersson, T.B.; Ingelman-Sundberg, M. Transcriptional, functional, and mechanistic comparisons of stem cell-derived hepatocytes, heparg cells, and three-dimensional human hepatocyte spheroids as predictive in vitro systems for drug- 
induced liver injury. Drug Metabolism and Disposition 2017, 45, 419.

69. Meier, F.; Freyer, N.; Brzeszczynska, J.; Knöspel, F.; Armstrong, L.; Lako, M.; Greuel, S.; Damm, G.; Ludwig-Schwellinger, E.; Deschl, U., et al. Hepatic differentiation of human ipscs in different 3d models: A comparative study. Int. J. Mol. Med. 2017, 40, 1759-1771.

70. Urich, E.; Patsch, C.; Aigner, S.; Graf, M.; Iacone, R.; Freskgård, P.-O. Multicellular self-assembled spheroidal model of the blood brain barrier. Sci. Rep. 2013, 3, 1500.

71. Lin, R.-Z.; Chang, H.-Y. Recent advances in three-dimensional multicellular spheroid culture for biomedical research. Biotechnology Journal 2008, 3, 1172-1184.

72. Engler, A.J.; Sen, S.; Sweeney, H.L.; Discher, D.E. Matrix elasticity directs stem cell lineage specification. Cell 2006, 126, 677-689.

73. Caliari, S.R.; Burdick, J.A. A practical guide to hydrogels for cell culture. Nature Methods 2016, 13, 405.

74. Swift, B.; Pfeifer, N.D.; Brouwer, K.L.R. Sandwich-cultured hepatocytes: An in vitro model to evaluate hepatobiliary transporter-based drug interactions and hepatotoxicity. Drug Metab. Rev. 2010, 42, 446-471.

75. Hoare, T.R.; Kohane, D.S. Hydrogels in drug delivery: Progress and challenges. Polymer 2008, 49, 1993-2007.

76. Ravichandran, R.; Islam, M.M.; Alarcon, E.I.; Samanta, A.; Wang, S.; Lundstrom, P.; Hilborn, J.; Griffith, M.; Phopase, J. Functionalised type-i collagen as a hydrogel building block for bio-orthogonal tissue engineering applications. Journal of Materials Chemistry B 2016, 4, 318-326.

77. Hahn, S.K.; Oh, E.J.; Miyamoto, H.; Shimobouji, T. Sustained release formulation of erythropoietin using hyaluronic acid hydrogels crosslinked by michael addition. Int. J. Pharm. 2006, 322, 44-51.

78. Webber, M.J.; Appel, E.A.; Meijer, E.W.; Langer, R. Supramolecular biomaterials. Nature Materials 2015, 15, 13.

79. Lee, K.Y.; Mooney, D.J. Alginate: Properties and biomedical applications. Progress in Polymer Science 2012, 37, 106-126. 
80. Choi, N.W.; Cabodi, M.; Held, B.; Gleghorn, J.P.; Bonassar, L.J.; Stroock, A.D. Microfluidic scaffolds for tissue engineering. Nature Materials 2007, 6, 908.

81. Mizuno, H.; Roy, A.K.; Zaporojan, V.; Vacanti, C.A.; Ueda, M.; Bonassar, L.J. Biomechanical and biochemical characterization of composite tissue-engineered intervertebral discs. Biomaterials 2006, 27, 362-370.

82. Yamada, M.; Utoh, R.; Ohashi, K.; Tatsumi, K.; Yamato, M.; Okano, T.; Seki, M. Controlled formation of heterotypic hepatic micro-organoids in anisotropic hydrogel microfibers for longterm preservation of liver-specific functions. Biomaterials 2012, 33, 8304-8315.

83. Okuzaki, H. General theory of gel preparation. In Gels handbook 1st ed.; Osada, Y., Ed. Academic Press: New York, 2001; pp 98118.

84. Ling, Y.; Rubin, J.; Deng, Y.; Huang, C.; Demirci, U.; Karp, J.M.; Khademhosseini, A. A cell-laden microfluidic hydrogel. Lab on a Chip 2007, 7, 756-762.

85. Rahfoth, B.; Weisser, J.; Sternkopf, F.; Aigner, T.; von der Mark, K.; Bräuer, R. Transplantation of allograft chondrocytes embedded in agarose gel into cartilage defects of rabbits. Osteoarthritis Cartilage 1998, 6, 50-65.

86. Haessler, U.; Kalinin, Y.; Swartz, M.A.; Wu, M. An agarose-based microfluidic platform with a gradient buffer for $3 \mathrm{~d}$ chemotaxis studies. Biomed. Microdev. 2009, 11, 827-835.

87. Park, D.; Park, J.; Jang, H.; Cheng, J.; Kim, S.H.; Lee, S.-H. Simultaneous microfluidic spinning of multiple strands of submicron fiber for the production of free-standing porous membranes for biological application. Biofabrication 2017, 9, 025026.

88. He, J.; Mao, M.; Liu, Y.; Shao, J.; Jin, Z.; Li, D. Fabrication of nature-inspired microfluidic network for perfusable tissue constructs. Advanced Healthcare Materials 2013, 2, 1108-1113.

89. Wu, J.; Chen, Q.; Liu, W.; Zhang, Y.; Lin, J.-M. Cytotoxicity of quantum dots assay on a microfluidic $3 \mathrm{~d}$-culture device based on 
modeling diffusion process between blood vessels and tissues. Lab on a Chip 2012, 12, 3474-3480.

90. Bersini, S.; Jeon, J.S.; Dubini, G.; Arrigoni, C.; Chung, S.; Charest, J.L.; Moretti, M.; Kamm, R.D. A microfluidic $3 \mathrm{~d}$ in vitro model for specificity of breast cancer metastasis to bone. Biomaterials 2014, 35, 2454-2461.

91. Prodanov, L.; Jindal, R.; Bale, S.S.; Hegde, M.; McCarty, W.J.; Golberg, I.; Bhushan, A.; Yarmush, M.L.; Usta, O.B. Long-term maintenance of a microfluidic $3 \mathrm{~d}$ human liver sinusoid. Biotechnol. Bioeng. 2016, 113, 241-246.

92. Oh, S.; Ryu, H.; Tahk, D.; Ko, J.; Chung, Y.; Lee, H.K.; Lee, T.R.; Jeon, N.L. "Open-top" microfluidic device for in vitro threedimensional capillary beds. Lab on a Chip 2017, 17, 3405-3414.

93. Jeon, J.S.; Bersini, S.; Whisler, J.A.; Chen, M.B.; Dubini, G.; Charest, J.L.; Moretti, M.; Kamm, R.D. Generation of $3 \mathrm{~d}$ functional microvascular networks with human mesenchymal stem cells in microfluidic systems. Integ. Biol. 2014, 6, 555-563.

94. Qin, J.; Wang, Y.; Wang, L.; Zhu, Y. Human brain organoid-on-achip to model prenatal nicotine exposure. Lab on a Chip 2018.

95. Lanz, H.L.; Saleh, A.; Kramer, B.; Cairns, J.; Ng, C.P.; Yu, J.; Trietsch, S.J.; Hankemeier, T.; Joore, J.; Vulto, P., et al. Therapy response testing of breast cancer in a $3 \mathrm{~d}$ high-throughput perfused microfluidic platform. BMC Cancer 2017, 17, 709.

96. Cuchiara, M.P.; Gould, D.J.; McHale, M.K.; Dickinson, M.E.; West, J.L. Integration of self-assembled microvascular networks with microfabricated peg-based hydrogels. Advanced Functional Materials 2012, 22, 4511-4518.

97. Sala, A.; Hanseler, P.; Ranga, A.; Lutolf, M.P.; Voros, J.; Ehrbar, M.; Weber, F.E. Engineering $3 \mathrm{~d}$ cell instructive microenvironments by rational assembly of artificial extracellular matrices and cell patterning. Integ. Biol. 2011, 3, 1102-1111.

98. Yang, X.; Li, K.; Zhang, X.; Liu, C.; Guo, B.; Wen, W.; Gao, X. Nanofiber membrane supported lung-on-a-chip microdevice for anti-cancer drug testing. Lab on a Chip 2018, 18, 486-495. 
99. Costello, C.M.; Sorna, R.M.; Goh, Y.-L.; Cengic, I.; Jain, N.K.; March, J.C. 3-d intestinal scaffolds for evaluating the therapeutic potential of probiotics. Mol. Pharm. 2014, 11, 2030-2039.

100. Skardal, A.; Devarasetty, M.; Soker, S.; Hall, A.R. In situ patterned micro 3d liver constructs for parallel toxicology testing in a fluidic device. Biofabrication 2015, 7, 031001.

101. Sriram, G.; Alberti, M.; Dancik, Y.; Wu, B.; Wu, R.; Feng, Z.; Ramasamy, S.; Bigliardi, P.L.; Bigliardi-Qi, M.; Wang, Z. Fullthickness human skin-on-chip with enhanced epidermal morphogenesis and barrier function. Materials Today 2017.

102. Verhulsel, M.; Vignes, M.; Descroix, S.; Malaquin, L.; Vignjevic, D.M.; Viovy, J.-L. A review of microfabrication and hydrogel engineering for micro-organs on chips. Biomaterials 2014, 35, 1816-1832.

103. March, S.; Ramanan, V.; Trehan, K.; Ng, S.; Galstian, A.; Gural, N.; Scull, M.A.; Shlomai, A.; Mota, M.M.; Fleming, H.E., et al. Micropatterned coculture of primary human hepatocytes and supportive cells for the study of hepatotropic pathogens. Nat. Protoc. 2015, 10, 2027.

104. Lee, P.J.; Hung, P.J.; Lee, L.P. An artificial liver sinusoid with a microfluidic endothelial-like barrier for primary hepatocyte culture. Biotechnol. Bioeng. 2007, 97, 1340-1346.

105. Ong, S.-M.; Zhang, C.; Toh, Y.-C.; Kim, S.H.; Foo, H.L.; Tan, C.H.; van Noort, D.; Park, S.; Yu, H. A gel-free 3d microfluidic cell culture system. Biomaterials 2008, 29, 3237-3244.

106. Bergstrom, G.; Nilsson, K.; Mandenius, C.F.; Robinson, N.D. Macroporous microcarriers for introducing cells into a microfluidic chip. Lab on a Chip 2014, 14, 3502-3504.

107. Faley, S.L.; Copland, M.; Wlodkowic, D.; Kolch, W.; Seale, K.T.; Wikswo, J.P.; Cooper, J.M. Microfluidic single cell arrays to interrogate signalling dynamics of individual, patient-derived hematopoietic stem cells. Lab on a Chip 2009, 9, 2659-2664.

108. Jackson-Holmes, E.L.; McDevitt, T.C.; Lu, H. A microfluidic trap array for longitudinal monitoring and multi-modal phenotypic analysis of individual stem cell aggregates. Lab on a Chip 2017, 17, 3634-3642. 
109. Griep, L.M.; Wolbers, F.; de Wagenaar, B.; ter Braak, P.M.; Weksler, B.B.; Romero, I.A.; Couraud, P.O.; Vermes, I.; van der Meer, A.D.; van den Berg, A. Bbb on chip: Microfluidic platform to mechanically and biochemically modulate blood-brain barrier function. Biomed. Microdev. 2013, 15, 145-150.

110. Booth, R.; Kim, H. Characterization of a microfluidic in vitro model of the blood-brain barrier ( $\mu \mathrm{bbb})$. Lab Chip 2012, 12, 17841792.

111. Brown, J.A.; Pensabene, V.; Markov, D.A.; Allwardt, V.; Neely, M.D.; Shi, M.; Britt, C.M.; Hoilett, O.S.; Yang, Q.; Brewer, B.M., et al. Recreating blood-brain barrier physiology and structure on chip: A novel neurovascular microfluidic bioreactor. Biomicrofluidics 2015, 9, 054124.

112. Kim, H.J.; Huh, D.; Hamilton, G.; Ingber, D.E. Human gut-on-achip inhabited by microbial flora that experiences intestinal peristalsis-like motions and flow. Lab on a Chip 2012, 12, 21652174.

113. Wufuer, M.; Lee, G.; Hur, W.; Jeon, B.; Kim, B.J.; Choi, T.H.; Lee, S. Skin-on-a-chip model simulating inflammation, edema and drug-based treatment. Sci. Rep. 2016, 6, 37471.

114. Lee, J.S.; Romero, R.; Han, Y.M.; Kim, H.C.; Kim, C.J.; Hong, J.-S.; Huh, D. Placenta-on-a-chip: A novel platform to study the biology of the human placenta. The Journal of Maternal-Fetal $\mathcal{E}$ Neonatal Medicine 2016, 29, 1046-1054.

115. Novosel, E.C.; Kleinhans, C.; Kluger, P.J. Vascularization is the key challenge in tissue engineering. Advanced Drug Delivery Reviews 2011, 63, 300-311.

116. DeCicco-Skinner, K.L.; Henry, G.H.; Cataisson, C.; Tabib, T.; Gwilliam, J.C.; Watson, N.J.; Bullwinkle, E.M.; Falkenburg, L.; O'Neill, R.C.; Morin, A., et al. Endothelial cell tube formation assay for the in vitro study of angiogenesis. 2014, e51312.

117. Liu, Y.; Senger, D.R. Matrix-specific activation of src and rho initiates capillary morphogenesis of endothelial cells. The FASEB Journal 2004, 18, 457-468.

118. Mebazaa, A.; Mayoux, E.; Maeda, K.; Martin, L.D.; Lakatta, E.G.; Robotham, J.L.; Shah, A.M. Paracrine effects of endocardial 
endothelial cells on myocyte contraction mediated via endothelin. American Journal of Physiology-Heart and Circulatory Physiology 1993, 265, H1841-H1846.

119. Kim, S.; Lee, H.; Chung, M.; Jeon, N.L. Engineering of functional, perfusable $3 \mathrm{~d}$ microvascular networks on a chip. Lab on a Chip 2013, 13, 1489-1500.

120. Phan, D.T.T.; Wang, X.; Craver, B.M.; Sobrino, A.; Zhao, D.; Chen, J.C.; Lee, L.Y.N.; George, S.C.; Lee, A.P.; Hughes, C.C.W. A vascularized and perfused organ-on-a-chip platform for largescale drug screening applications. Lab on a Chip 2017, 17, 511-520.

121. Kolesky, D.B.; Homan, K.A.; Skylar-Scott, M.A.; Lewis, J.A. Three-dimensional bioprinting of thick vascularized tissues. Proceedings of the National Academy of Sciences 2016, 113, 3179.

122. Yum, K.; Hong, S.G.; Healy, K.E.; Lee, L.P. Physiologically relevant organs on chips. Biotechnology Journal 2014, 9, 16-27.

123. Konar, D.; Devarasetty, M.; Yildiz, D.V.; Atala, A.; Murphy, S.V. Lung-on-a-chip technologies for disease modeling and drug development: Supplementary issue: Image and video acquisition and processing for clinical applications. Biomedical Engineering and Computational Biology 2016, 7s1, BECB.S34252.

124. Kujala, V.J.; Pasqualini, F.S.; Goss, J.A.; Nawroth, J.C.; Parker, K.K. Laminar ventricular myocardium on a microelectrode array-based chip. Journal of Materials Chemistry B 2016, 4, 35343543.

125. Vassallo, A.; Chiappalone, M.; De Camargos Lopes, R.; Scelfo, B.; Novellino, A.; Defranchi, E.; Palosaari, T.; Weisschu, T.; Ramirez, T.; Martinoia, S., et al. A multi-laboratory evaluation of microelectrode array-based measurements of neural network activity for acute neurotoxicity testing. Neurotoxicology 2017, 60, 280-292.

126. Maoz, B.M.; Herland, A.; Henry, O.Y.F.; Leineweber, W.D.; Yadid, M.; Doyle, J.; Mannix, R.; Kujala, V.J.; FitzGerald, E.A.; Parker, K.K., et al. Organs-on-chips with combined multielectrode array and transepithelial electrical resistance measurement capabilities. Lab on a Chip 2017, 17, 2294-2302. 
127. Bavli, D.; Prill, S.; Ezra, E.; Levy, G.; Cohen, M.; Vinken, M.; Vanfleteren, J.; Jaeger, M.; Nahmias, Y. Real-time monitoring of metabolic function in liver-on-chip microdevices tracks the dynamics of mitochondrial dysfunction. Proceedings of the National Academy of Sciences 2016, 113, E2231.

128. Lind, J.U.; Yadid, M.; Perkins, I.; O'Connor, B.B.; Eweje, F.; Chantre, C.O.; Hemphill, M.A.; Yuan, H.; Campbell, P.H.; Vlassak, J.J., et al. Cardiac microphysiological devices with flexible thin-film sensors for higher-throughput drug screening. Lab on a Chip 2017, 17, 3692-3703.

129. Zhang, Y.S.; Aleman, J.; Shin, S.R.; Kilic, T.; Kim, D.; Mousavi Shaegh, S.A.; Massa, S.; Riahi, R.; Chae, S.; Hu, N., et al. Multisensor-integrated organs-on-chips platform for automated and continual in situ monitoring of organoid behaviors. Proceedings of the National Academy of Sciences 2017.

130. del Campo, A.; Greiner, C. Su-8: A photoresist for high-aspectratio and $3 \mathrm{~d}$ submicron lithography. Journal of Micromechanics and Microengineering 2007, 17, R81.

131. Xia, Y.; Whitesides, G.M. Soft lithography. Angewandte Chemie International Edition 1998, 37, 550-575.

132. Qin, D.; Xia, Y.; Whitesides, G.M. Soft lithography for micro- and nanoscale patterning. Nat. Protoc. 2010, 5, 491.

133. Halldorsson, S.; Lucumi, E.; Gomez-Sjoberg, R.; Fleming, R.M. Advantages and challenges of microfluidic cell culture in polydimethylsiloxane devices. Biosens. Bioelectron. 2015, 63, 218231.

134. Carlborg, C.F.; Haraldsson, T.; Oberg, K.; Malkoch, M.; van der Wijngaart, W. Beyond pdms: Off-stoichiometry thiol-ene (oste) based soft lithography for rapid prototyping of microfluidic devices. Lab on a Chip 2011, 11, 3136-3147.

135. Hung, L.-H.; Lin, R.; Lee, A.P. Rapid microfabrication of solventresistant biocompatible microfluidic devices. Lab on a Chip 2008, 8, 983-987.

136. Jang, K.-J.; Mehr, A.P.; Hamilton, G.A.; McPartlin, L.A.; Chung, S.; Suh, K.-Y.; Ingber, D.E. Human kidney proximal tubule-on-a- 
chip for drug transport and nephrotoxicity assessment. Integ. Biol. 2013, 5, 1119-1129.

137. Kenis, P.J.A.; Ismagilov, R.F.; Whitesides, G.M. Microfabrication inside capillaries using multiphase laminar flow patterning. Science 1999, 285, 83.

138. Atencia, J.; Beebe, D.J. Controlled microfluidic interfaces. Nature 2004, 437, 648.

139. Han, J.; Jun, Y.; Kim, S.H.; Hoang, H.-H.; Jung, Y.; Kim, S.; Kim, J.; Austin, R.H.; Lee, S.; Park, S. Rapid emergence and mechanisms of resistance by $\mathrm{u} 87$ glioblastoma cells to doxorubicin in an in vitro tumor microfluidic ecology. Proceedings of the National Academy of Sciences 2016, 113, 1428314288.

140. Lee, C.-Y.; Chang, C.-L.; Wang, Y.-N.; Fu, L.-M. Microfluidic mixing: A review. Int. J. Mol. Sci. 2011, 12.

141. Rasmussen, A.; M. Gaitan, M.; Locascio, E.L.; Zaghloul, E.M. Fabrication techniques to realize cmos-compatible microfluidic microchannels. Journal of Microelectromechanical Systems 2001, 10, 286-297.

142. Attia, U.M.; Marson, S.; Alcock, J.R. Micro-injection moulding of polymer microfluidic devices. Microfluid. Nanofluid. 2009, 7, 1.

143. Pemg, B.-Y.; Wu, C.-W.; Shen, Y.-K.; Lin, Y. Microfluidic chip fabrication using hot embossing and thermal bonding of cop. Polymers for Advanced Technologies 2010, 21, 457-466.

144. Yi, H.-G.; Lee, H.; Cho, D.-W. 3d printing of organs-on-chips. Bioengineering 2017, 4.

145. Ho, C.M.B.; Ng, S.H.; Li, K.H.H.; Yoon, Y.-J. 3d printed microfluidics for biological applications. Lab on a Chip 2015, 15, 3627-3637.

146. Haber, C. Microfluidics in commercial applications; an industry perspective. Lab on a Chip 2006, 6, 1118-1121.

147. Jung, W.; Han, J.; Choi, J.-W.; Ahn, C.H. Point-of-care testing (poct) diagnostic systems using microfluidic lab-on-a-chip technologies. Microelectronic Engineering 2015, 132, 46-57.

148. Kirby, B.J. Micro- and nanoscale fluid dynamics. $1^{\text {st }}$ ed.; Cambridge University Press: New York, 2010. 
149. Prescher, J.A.; Bertozzi, C.R. Chemistry in living systems. Nat. Chem. Biol. 2005, 1, 13.

150. Takahashi, A.; Suzuki, Y.; Suhara, T.; Omichi, K.; Shimizu, A.; Hasegawa, K.; Kokudo, N.; Ohta, S.; Ito, T. In situ cross-linkable hydrogel of hyaluronan produced via copper-free click chemistry. Biomacromolecules 2013, 14, 3581-3588.

151. Madl, C.M.; Katz, L.M.; Heilshorn, S.C. Bio-orthogonally crosslinked, engineered protein hydrogels with tunable mechanics and biochemistry for cell encapsulation. Advanced Functional Materials 2016, 26, 3612-3620.

152. Stoddart, M.J. Cell viability assays: Introduction. In Mammalian cell viability: Methods and protocols, Stoddart, M.J., Ed. Humana Press: Totowa, NJ, 2011; pp 1-6.

153. Crowther, J.R. Basic principles of elisa. In Elisa: Theory and practice, Crowther, J.R., Ed. Humana Press: Totowa, NJ, 1995; pp 35-61.

154. Acharya, T.; Ray, A.K. Image processing - principles and applications. John Wiley \& Sons, Inc.: Hoboken, NJ, 2005; Vol. 1st.

155. Yetisen, A.K.; Volpatti, L.R.; Coskun, A.F.; Cho, S.; Kamrani, E.; Butt, H.; Khademhosseini, A.; Yun, S.H. Entrepreneurship. Lab Chip 2015, 15, 3638-3660.

156. Mandenius, C.-F.; Björkman, M. Mechatronics design principles for biotechnology product development. Trends Biotechnol. 2010, 28, 230-236.

157. Mandenius, C.-F.; Björkman, M. Biomechatronic design in biotechnology - a methodology for development of biotechnological products. 1 ed.; Wiley: New York, NY, USA, 2011; p 304.

158. Zhang, B.; Radisic, M. Organ-on-a-chip devices advance to market. Lab on a Chip 2017, 17, 2395-2420.

159. Bauer, S.; Wennberg Huldt, C.; Kanebratt, K.P.; Durieux, I.; Gunne, D.; Andersson, S.; Ewart, L.; Haynes, W.G.; Maschmeyer, I.; Winter, A., et al. Functional coupling of human pancreatic islets and liver spheroids on-a-chip: Towards a novel human ex vivo type 2 diabetes model. Sci. Rep. 2017, 7, 14620.

160. Oleaga, C.; Bernabini, C.; Smith, A.S.T.; Srinivasan, B.; Jackson, M.; McLamb, W.; Platt, V.; Bridges, R.; Cai, Y.; Santhanam, N., et 
al. Multi-organ toxicity demonstration in a functional human in vitro system composed of four organs. Sci. Rep. 2016, 6, 20030. 


\section{Papers}

The papers associated with this thesis have been removed for copyright reasons. For more details about these see:

http://urn.kb.se/resolve?urn=urn:nbn:se:liu:diva-145300 